\title{
EVOLUÇÃO DA INFRAESTRUTURA GRAVIMÉTRICA NO BRASIL
}

\author{
EVOLUTION OF GRAVIMETRIC INFRASTRUCTURE IN BRAZIL
}

\author{
Carlos Alberto Correia e CASTRO JUNIOR ${ }^{1}$, Gabriel do Nascimento GUIMARÃES ${ }^{2}$, \\ Nilson Clementino FERREIRA ${ }^{1}$ \\ 1Pós-Graduação em Ciências Ambientais, Universidade Federal de Goiás, Campus Samambaia, Goiânia - GO. \\ Emails: correaecastrojr@gmail.com,nclferreira@gmail.com \\ ²Laboratório de Topografia e Geodésia, Universidade Federal de Uberlândia, Campus Monte Carmelo, Monte Carmelo - MG. \\ Email: gabriel@ufu.br \\ Introdução \\ Medição da Aceleração da Gravidade \\ Gravimetria Terrestre \\ Determinação Absoluta da Gravidade Terrestre \\ Gravímetros FG-5 e A-10 \\ Determinação Relativa da Gravidade Terrestre \\ Gravímetro LaCoste \& Romberg - modelo G \\ Gravímetro CG-5 \\ Gravimetria Satelital \\ LAGEOS - LAser GEOdynamics Satellite \\ CHAMP - CHAllenging Minisatellite Payload \\ GRACE - Gravity Recovery And Climate Experiment \\ GOCE - Gravity field and steady-state Ocean Circulation Explorer \\ Gravimetria Aérea e Marinha \\ Principais Instituições Brasileiras Produtoras de Gravimetria \\ Observatório Nacional (ON) \\ Agência Nacional de Petróleo, Gás Natural e Biocombustíveis (ANP) \\ Serviço Geológico do Brasil (CPRM) \\ Universidade Federal do Paraná (UFPR) \\ Universidade de São Paulo (USP) \\ Instituto Brasileiro de Geografia e Estatística (IBGE) \\ Conclusões \\ Referências
}

\begin{abstract}
RESUMO - Com o avanço das técnicas de medição da aceleração de gravidade, houve considerável aumento das aplicações gravimétricas em diversos segmentos de atividades mundo afora. Por conseguinte, uma profusão de dados gravimétricos espaciais, aéreos, marinhos e terrestres tem sido adquirida, sobretudo desde meados do século passado. Ao desafio de aprimorar as aplicações, soma-se o interesse da comunidade científica em estabelecer padrões acerca da aquisição e manutenção do acervo auferido, visando dar maior homogeneidade às informações obtidas e disponibilizadas ao usuário. No quadro brasileiro, a falta de uma política gravimétrica nacional tem acarretado iniciativas difusas, fazendo com que cada instituição preencha suas necessidades de forma independente e sem a devida padronização. O presente artigo visa trazer à tona informações que possibilitem um melhor conhecimento das atividades gravimétricas até então empreendidas em território brasileiro, retratando as principais técnicas e instrumentos utilizados. Adicionalmente, retrata-se brevemente a trajetória das principais instituições que atuam no campo da gravimetria, no intuito de conhecer o passado, compreender o presente e antever futuras ações devidamente concatenadas.

Palavras-chave: Gravimetria; Gravímetro; Aceleração de Gravidade.
\end{abstract}

ABSTRACT - With the advancement of gravity acceleration measurement techniques, there has been considerable increase of gravimetric applications in various segments of activities around the world. Therefore, a profusion of spatial gravity data, aerial, marine and land has been acquired, especially since the middle of last century. The challenge of improving the application adds to the interest of the scientific community to establish standards on the acquisition and maintenance of earned assets, to ensure greater homogeneity of the information obtained and made available to users. In the Brazilian context, the lack of a gravimetric national policy has led to diffuse initiatives, leading each institution to meet their needs independently and without proper standardization. This article aims to bring to light information that allows a better understanding of gravimetric activities hitherto undertaken in Brazil, portraying the main techniques and instruments used. Additionally, is portrayed briefly the trajectory of the main institutions working in the field of gravity in order to know the past, understand the present and anticipate future actions properly concatenated. Keywords: Gravimetry; Gravity meter; Gravity acceleration.

\section{INTRODUÇÃO}

A gravidade é onipresente, incidindo sobre todos os seres vivos e em qualquer lugar do mundo. Seus efeitos produzem alguma influência nos mais variados segmentos das atividades cotidianas. Inúmeros estudos envolvendo a aceleração de gravidade têm sido conduzidos através dos tempos, trazendo à tona uma infinidade de aplicações que, em última análise, podem ajudar à humanidade a interagir melhor com o planeta Terra.
A partir de meados do século XX houve um avanço considerável nas técnicas voltadas à determinação da gravidade, melhorando gradativamente a precisão dos resultados auferidos e acarretando numa profusão de levantamentos gravimétricos espaciais, aerotransportados, marinhos e, principalmente, terrestres. Por conseguinte, a cada dia que passa surgem novos empregos para aceleração de gravidade, ampliando os horizontes de diversas 
ciências, com destaque às atividades ambientais, arqueológicas, cartográficas, de engenharia, geodésicas, geofísicas, mineralógicas e petrolíferas. No Brasil, a falta de uma política gravimétrica nacional tem gerado alguns inconvenientes correlacionados à duplicidade de esforços e à designação de diretrizes concatenadas. Em decorrência, a comunidade usuária não tem uma visão clara do que existe disponível em termos de acervos gravimétricos e ainda se ressente de mecanismos mais eficazes de utilização de todos esses dados.

Indo ao encontro dessas circunstâncias, o presente artigo pretende discorrer sobre a evolução da gravimetria no Brasil, enfocando aspectos pregressos, atuais e futuros das principais instituições, técnicas e equipamentos envolvidos com a produção gravimétrica em terras brasileiras. Destaca-se que não existe um documento que retrate essas informações, razão pela qual, pretende-se preencher, ao menos parcialmente, as lacunas até então existentes.

Inicialmente, são apresentadas generalidades sobre a medição de gravidade, com as principais áreas de aplicação. Em seguida, as modalidades de determinação gravimétrica são delineadas, indicando características, mecanismos e principais equipamentos usados no Brasil e no mundo. Em seguida, são tratadas as instituições brasileiras que mais se destacam no contexto gravimétrico nacional. Concluindo, algumas perspectivas futuras são apontadas.

Ante a natureza informativa do artigo, tratando de informações tanto minuciosas quanto abrangentes, buscou-se maior ênfase às conotações geodésicas que o tema propicia. Adicionalmente, destacam-se as dificuldades encontradas nas tentativas de recuperação de informações institucionais pregressas, pela falta de documentação afim ou mesmo de profissionais ainda atuantes que conheçam com detalhes o que ocorreu no passado.

\section{MEDIÇÃO DA ACELERAÇÃO DE GRAVIDADE}

A força de gravidade é um fenômeno universal e, em nosso planeta, ocorre basicamente devido à atração das massas terrestres e da força centrífuga advinda da rotação da Terra (Dehlinger, 1978). Depreende-se então que o campo de gravidade se manifesta no interior da crosta, nos oceanos e massas d’água, na superfície e nas camadas de ar circundantes.

A força de gravidade sempre despertou considerável interesse da humanidade, sendo tratada por grandes pensadores, tais como o filósofo grego Aristóteles (384 - 322 a.C), o primeiro a descrever fenômenos práticos correlacionados com a aceleração de gravidade " $g$ ", Galileu Galilei, Leonardo da Vinci e Isaac Newton. É sempre oportuno mencionar que o planeta Terra assumiu sua forma atual sob a ação da força de gravidade (Torge, 2001).

Galilei introduziu dois métodos de medidas absolutas: pendular e "queda-livre" (free-fall). O método pendular foi utilizado para realizar a primeira medição da aceleração de gravidade no observatório de Potsdam, Alemanha, em 1906. A expressão do movimento do pêndulo é a seguinte:

$$
T=2 \pi \sqrt{\frac{l}{g}}
$$

onde $T$ é o período, $l$ o comprimento e $g$ a aceleração de gravidade. A partir do comprimento do pêndulo e de uma série de observações do período do movimento durante certo intervalo de tempo, obtém-se o valor de " $g$ " por meio de um método de ajustamento de observações (Gemael, 1999; Torge, 2001).

O valor de " $g$ " na superfície terrestre varia proporcionalmente à distância ao centro da Terra. Em tese, um corpo situado na linha do equador sofre menos influência da gravidade do que nos polos. Isso implica em dizer que a latitude e altitude são grandes responsáveis pela variação de “ $g$ ". Entretanto, as diferenças de densidades em massas existentes no interior e exterior da crosta terrestre também interferem nessas magnitudes.

Motivados por razões científicas e econômicas, vários segmentos da sociedade se ocupam do estudo do campo de gravidade e da consequente determinação de " $g$ ". A empresa norte-americana Micro-g LaCoste (http://microg la coste. com/), provavelmente a maior fabricante mundial de equipamentos gravimétricos, destaca algumas aplicações por áreas de estudo:

- Monitoramento Ambiental: monitoramento do lençol freático em aquíferos; gestão dos resíduos nucleares e análises do nível global do mar.

- Gestão de Recursos Minerais: exploração de petróleo e prospecção mineral.

- Geofísica: detecção de movimentos crustais; monitoramento de magma vulcânico; estudos de 
subducção de placas e investigação de terremotos.

- Calibrações de Precisão: padronização do quilograma no sistema internacional; transdutor de pressão e célula de carga de calibração.

- Geodésia: determinação do geoide; construções de redes gravimétricas; elaboração de modelos geoidais e do geopotencial.

Em paralelo, outras aplicações promissoras e não menos importantes concernentes à engenharia, geotectônica, hidrologia e arqueologia ampliam cada vez mais o uso das medições de gravidade.

A ciência que se incumbe precipuamente do estudo e determinação da gravidade é denominada Gravimetria. Etimologicamente gravimetria significa medida de um peso. Pode ser definida como sendo o conjunto de técnicas e procedimentos voltados ao estudo da aceleração de gravidade (Castro Junior, 2005). Por sua vez, Coyago (2010), define como a ciência que estuda as variações do campo de gravidade. Uma maneira usual de se abordar a questão da medição de “ $g$ " pressupõe métodos gravimétricos terrestres, aéreos, marinhos e satelitais. Pretendese discorrer sobre cada uma dessas modalidades, com justificada ênfase à componente terrestre, apresentando as principais características e instrumentos empregados no território nacional, bem como apresentar os trabalhos e resultados atuais relacionados à gravimetria.

\section{Gravimetria Terrestre}

As primeiras medições terrestres acuradas de " $g$ " foram efetuadas com dispositivos pendulares. Embora o primeiro relógio pendular tenha sido construído em 1657 por Christian Huygens, foi somente em 1672 que o astrônomo francês Richer, obteve um valor absoluto de gravidade através da oscilação de um pêndulo, na Guiana Francesa (Dehlinger, 1978; Coyago, 2010). De acordo com Thomas (1966), tais medições ajudaram a embasar as teorias iniciais de que a Terra seria achatada nos polos. Em terras brasileiras, atribui-se ao geógrafo francês Pierre Couplet a primeira determinação gravimétrica na Paraíba, no ano de 1698, utilizando também um dispositivo pendular; essas medições foram mencionadas por Newton, defensor da premissa do achatamento polar, no volume III dos seus Philosophiae naturalis principia mathematica, na edição de 1713 (Moreira, 1991).

Com o passar dos anos, várias maneiras de se medir " $g$ " foram sendo criadas e aperfeiçoadas, culminando com a produção em série de instrumentos específicos para aquele fim, denominados gravímetros. Até aproximadamente 1920, tais medições eram conduzidas com instrumentos pendulares e balanças de torção que, além de demoradas, restringiam-se a regiões de fácil acesso (Torge, 1989). Na terceira década do século passado surgem os primeiros gravímetros mecânicos que permitiram uma verdadeira revolução na medição de gravidade e disponibilizavam resultados dez vezes superiores aos dispositivos pendulares (Gemael, 1999). A partir de então uma profusão de estações gravimétricas foram determinadas em vários recantos do mundo, inclusive no Brasil. A figura 1 (a) ilustra a quantidade de medidas gravimétricas registradas do início de 1800 a meados da década de 1980, enquanto que a figura 1 (b) apresenta a precisão dessas medidas, correlacionando com o tipo e marca dos principais equipamentos.

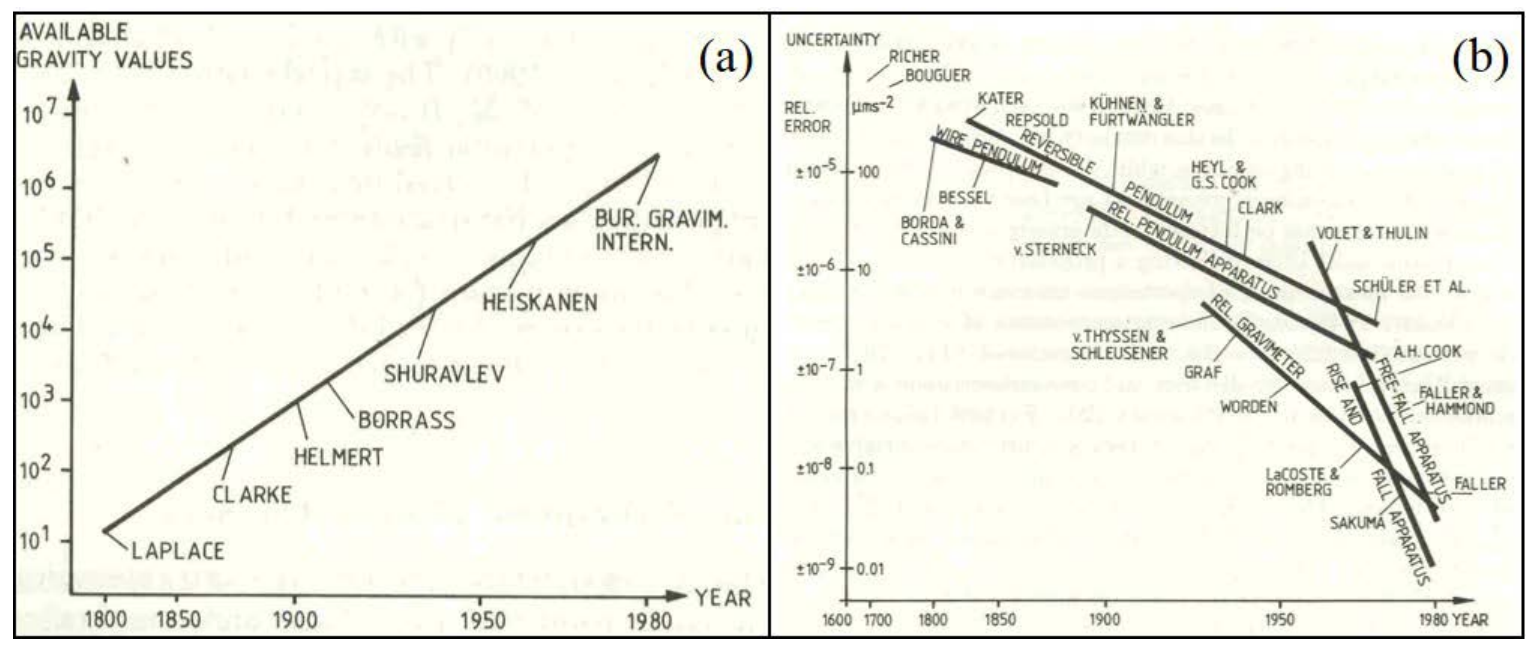

Figura 1 - Dados gravimétricos disponíveis de 1800 a 1980 (a) e incertezas das medidas para o mesmo período (b) (Torge, 1989). 
O alvorecer deste século XXI testemunhou consideráveis avanços nessas determinações e, a cada dia que passa, vislumbram-se novas aplicações em variados ramos da atividade humana. Normalmente as estações gravimétricas distribuídas na superfície da Terra estão organizadas em redes. No Brasil existem diversas concepções para as redes gravimétricas. Entretanto, independentemente da nomenclatura utilizada, há um consenso de que há duas grandes modalidades de redes gravimétricas no contexto terrestre: redes absolutas e redes relativas. Detalhamento sobre os tipos de redes gravimétricas existentes e propostas, podem ser obtidos em Mello, 1973; Rosier, 1979; Trabanco, 1995; Gemael, 1999; Santos Junior, 2005; Castro Junior, 2005 e Luz, 2008.

\section{Determinação Absoluta da Gravidade Terrestre}

Nesta modalidade o valor de "g" é obtido diretamente do instrumental empregado. Há duas formas clássicas para se determinar a gravidade absoluta: utilizando dispositivos pendulares, já em desuso, e por meio da queda livre de um corpo. Conforme Gemael (1999), a partir do momento em que foi possível a medição acurada de intervalos infinitesimais de tempo e distância de um corpo em queda livre, a modalidade de determinação absoluta que empregava a queda de um corpo, ganhou notoriedade; isso ocorre até os dias atuais.

No panorama geodésico mundial, o conjunto de estações gravimétricas absolutas compõe a Rede de Referência de Gravidade Absoluta e representa o que de mais preciso existe em termos de referencial. No Brasil tal rede de referência é traduzida pela Rede Nacional de Estações Gravimétricas Absolutas (RENEGA). Com vistas aos objetivos deste artigo, torna-se conveniente apenas uma abordagem sumária dos equipamentos absolutos existentes em território brasileiro.

\section{Gravímetros FG-5 e A-10}

Produzido pela Micro-g LaCoste desde 1995, o FG5 (Figura 2a) passou a ser o equipamento mais acurado para as medições absolutas de " $g$ " disponível no Brasil. O princípio de funcionamento considera um corpo em queda livre numa câmara de vácuo de $0,33 \mathrm{~m}$ de comprimento. A posição deste corpo durante a queda é traduzida em franjas óticas e monitorada com grande precisão por um processo interferométrico a laser e por um relógio atômico de rubídio. Em 2004 o Observatório Nacional (ON) adquiriu este único exemplar que foi instalado no Laboratório de Gravimetria existente na cidade de Vassouras, estado do Rio de Janeiro.

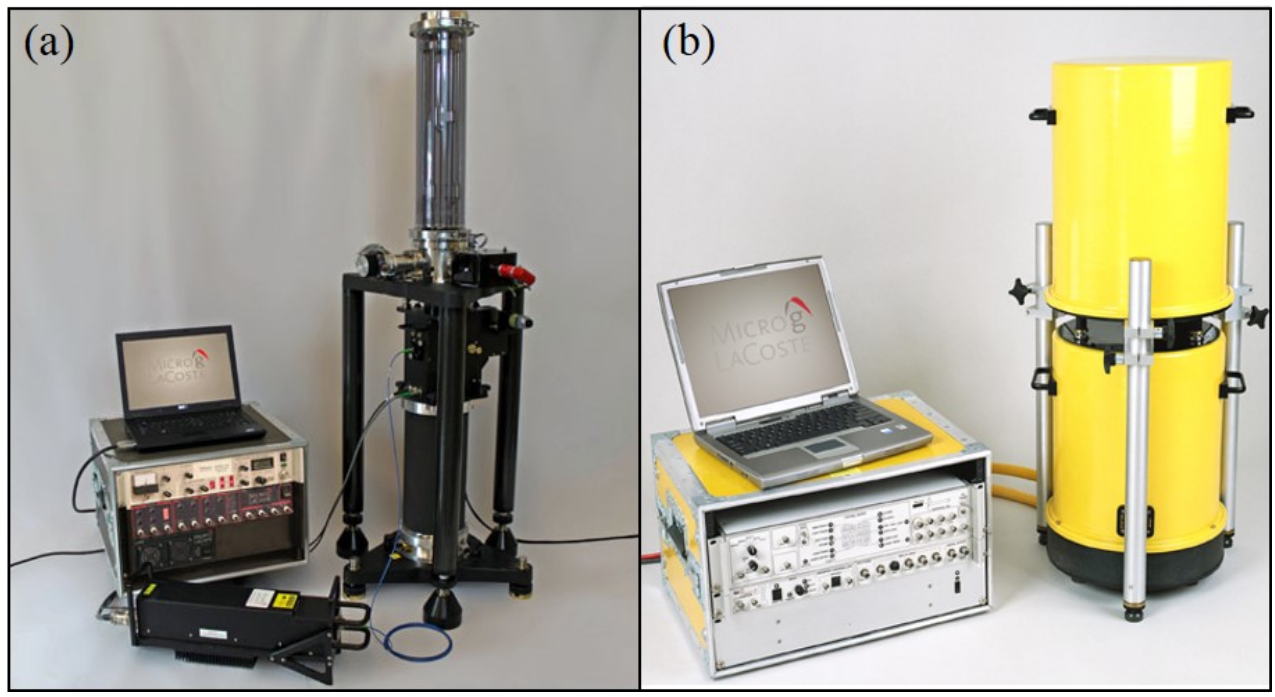

Figura 2 - Gravímetro FG-5 (a) e gravímetro A-10 (b) (www.microglacoste.com).

Outro equipamento presente no território brasileiro é o gravímetro A-10. O método de operação do A-10 é semelhante ao empregado pelo FG5 e considera também um corpo em queda livre numa câmara de vácuo com um preciso controle interferométrico de posição, utilizando um feixe de laser e um relógio atômico. Uma das principais características desse gravímetro diz respeito à portabilidade, permitindo deslocar o equipamento em viaturas convenientemente preparadas. Embora o fabricante, a empresa Micro-g LaCoste, informe que o A-10 tenha sido projetado para operar mesmo em condições severas, medições recentes 
efetuadas pelos autores com o equipamento de número 32, denotam que, na prática, as condições de estabilidade das estações, aliadas aos fatores climáticos, interferem na qualidade das observações. Em decorrência, estações com bases estáveis e abrigadas do sol, chuvas e ventos devem ser preferidas para que se possam obter resultados mais apropriados. Paralelamente, os inúmeros componentes mecânicos e eletrônicos são bastante sensíveis e requerem ajustes amiúde.

Por conseguinte, no manuseio e deslocamentos com o equipamento, as atenções e cuidados devem ser redobrados e eventuais manutenções preventivas e corretivas devem fazer parte de sua rotina operacional. Há duas unidades desse equipamento no Brasil, uma pertence ao $\mathrm{ON}$ e a segunda, adquirida pelo governo de São Paulo, é operada pela Escola Politécnica da Universidade de São Paulo (EPUSP). A figura 2b mostra os módulos principais de um A-10: a parte superior chamada de Dropper, onde há a câmara de vácuo; a parte inferior denominada IB, Interferometer Baser; e a Central de Controle, acompanhada de um notebook, que monitora o funcionamento do equipamento.

\section{Determinação Relativa da Gravidade Terrestre}

Como a própria denominação sugere, nas determinações relativas são medidas diferenças de " $g$ " ao invés de grandezas absolutas. O princípio de funcionamento da maior parte desses instrumentos pressupõe que o peso de um corpo, sustentado por um sistema elástico, seja contraposto à força de gravidade. Assim que o sistema entra em equilíbrio, as observações podem ser realizadas. Desta forma, medições empreendidas entre dois ou mais sítios permitem que as correspondentes diferenças de gravidade sejam deduzidas.

Para que essas medições diferenciais ou relativas façam sentido no contexto geodésico, torna-se imprescindível que haja, ao menos, uma estação de referência com o valor de " $g$ " conhecido, inserida nos circuitos gravimétricos. Tais estações fazem parte das redes de referência de gravidade. As redes de referência ditas relativas, menos acuradas do que as redes absolutas, são determinadas a partir de gravímetros relativos. Destaque merecido deve ser dado à antiga, mas importante, International Gravity Standardization Net (IGSN), implantada em âmbito mundial no ano de 1971. A IGSN71, como é mais conhecida, é abordada em diversas fontes (ver Morelli, 1971).

Complementando, cabe ressaltar que a maioria das estações gravimétricas relativas estabelecidas no mundo pertence à chamada Rede de Densificação.

Os gravímetros relativos são produzidos em série há mais de oitenta anos e vêm, desde então, atendendo às necessidades práticas da comunidade usuária. Embora menos precisos do que os absolutos, via de regra são mais leves, portáteis e consideravelmente mais baratos. Estima-se que haja algumas dezenas desses equipamentos distribuídos pelo Brasil.

Exceções à regra ficam por conta de gravímetros destinados ao monitoramento da crosta terrestre, como o Supercondutor e o Gphone que, embora sejam instrumentos relativos, têm princípios de funcionamento diferenciados, custos bem mais elevados e podem ser considerados como uma categoria à parte.

\section{Gravímetro LaCoste \& Romberg - modelo G}

Em 1932, Lucien LaCoste e Arnold Romberg iniciaram o projeto de um sismógrafo vertical. LaCoste buscou melhorar o modelo de sismógrafo então existente, levando-o à concepção da chamada mola de comprimento zero, uma inovadora maneira de se avaliar a aceleração da gravidade. Segundo o físico Robert Hooke (1635 - 1703), uma mola seria capaz de exercer uma força proporcional ao comprimento de sua deformação, em sentido contrário, tal teoria redundou na lei de Hooke. LaCoste imaginou, então, uma mola pré-tensionada, contrariando as premissas de Hooke, fazendo com que a força exercida fosse proporcional ao comprimento total, e não apenas ao comprimento de deformação da mola.

Esse artefato revolucionou a concepção presente na idealização de sismógrafos e gravímetros e credenciou seu inventor a fundar a empresa LaCoste \& Romberg INC. Poucos anos se passaram até que a empresa ganhasse renome mundial e se consolidasse como a mais expressiva fábrica de instrumentos medidores de gravidade até o seu fechamento, por volta de 2010.

A versão Geodésica do gravímetro $L$ \& $R$, daí a denominação modelo $G$, foi concebida em meados do século passado com o intuito de efetuar medidas em qualquer ponto do planeta 
Terra. Desde então, tem demonstrado eficácia sob as mais variadas condições de temperatura, tornando-o apto a ser usado em qualquer lugar onde o ser humano tenha condições de interagir com o meio ambiente. Por essas e outras razões, esse equipamento foi, e continua sendo, o gravímetro mais difundido no mundo (Gemael, 1999; Castro Junior, 2005).

Em que pese a aparência um tanto simplificada, conforme se vê na Figura 3a, há grande complexidade em sua composição, exigindo redobrada atenção no trato com o equipamento. Teoricamente o manuseio do $L \& R$ é simples. Entretanto, para se proceder às calibrações e ajustes periódicos, é conveniente um operador experiente e meticuloso. Atenção adicional deve ser dada à posição da linha de leitura e aos cuidados requeridos antes, durante e depois das medições propriamente ditas.

O princípio de funcionamento encerra um sistema sensor composto por um conjunto de molas de quartzo e hastes que sustentam uma massa.

Esse mecanismo funciona em um ambiente teoricamente isolado de pressões atmosféricas externas e é apresentado na figura 3 (b) (c), fornecida pelo próprio fabricante e elucidada pelo texto subsequente. O gravímetro é termostatizado para estabilizar termicamente o sistema elástico. Por isso deve ser mantido a uma temperatura constante que é atingida automaticamente em duas horas. Contudo, as medições somente devem ser iniciadas depois de quatro horas após a conexão à corrente elétrica ou a uma bateria.

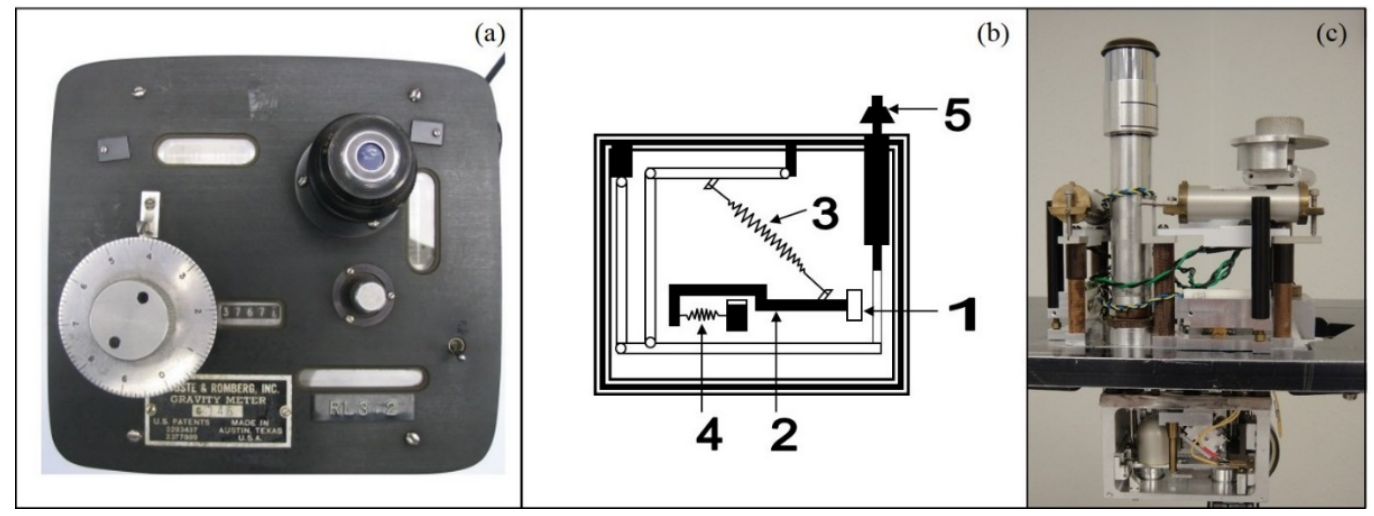

Figura 3 - Vista superior do gravímetro L\&R (a), mecanismo do gravímetro (b) e parte interna do equipamento (c)

O sistema sensor da gravidade consiste numa massa (1) presa à extremidade de uma barra horizontal (2) sustentada pela mola de comprimento nulo (3). A mola de amortecimento (4) forma um pivô flutuante, eliminando, com isso, qualquer fricção no sistema móvel.

\section{Gravímetros Scintrex}

Com uma proposta inovadora, a empresa canadense Scintrex trouxe ao mercado o gravímetro CG-5. Seu funcionamento é baseado em um sistema de molas de quartzo fundido que busca colocar uma massa em equilíbrio. Portátil e de fácil operação foi o substituto natural do antigo L\&R, sendo atualmente, até por falta de uma concorrência competitiva, o gravímetro mais comercializado no Brasil. Apostando num perfil eletrônico automatizado de medição e processamento, o CG-5 substituiu seu antecessor, o CG-3. Este, pouco difundido no Brasil. O CG-5 possibilita a obtenção de " $g$ " em poucos minutos com notável precisão (Figura 4). No entanto, determinados aspectos operacionais merecem ser comentados. Talvez pela grande quantidade de componentes eletrônicos, alguns desses equipamentos apresentaram problemas durante levantamentos conduzidos em condições severas, sobretudo em regiões úmidas e quentes, como é o caso da Amazônia.

Outra questão diz respeito ao desempenho heterogêneo dos aparelhos, fazendo com que uns apresentem melhores resultados do que outros. Tais circunstâncias acarretam a necessidade de um constante monitoramento dos resultados disponibilizados e ainda de cuidados adicionais por parte dos operadores, incluindo ajustes e calibrações periódicos.

Em 2016 a Scintrex divulgou a nova geração de gravímetro, intitulado CG-6 (Figura 5). Este equipamento possui recursos novos e aprimorados, tal como bluetooth e um computador tablet para operação remota, além de uma redução de $1 / 3$ no tamanho e peso, em comparação ao CG-5. O software de processamento (Lynx LG) também é uma novidade. Até o momento os autores desconhecem a presença deste modelo em território nacional. 


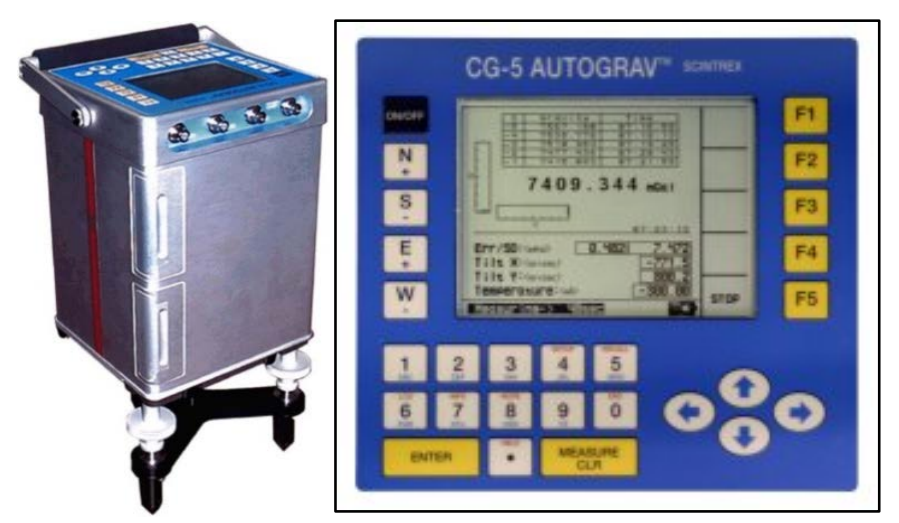

Figura 4 - Detalhes do gravímetro CG-5 (http://www.scintrexltd.com).

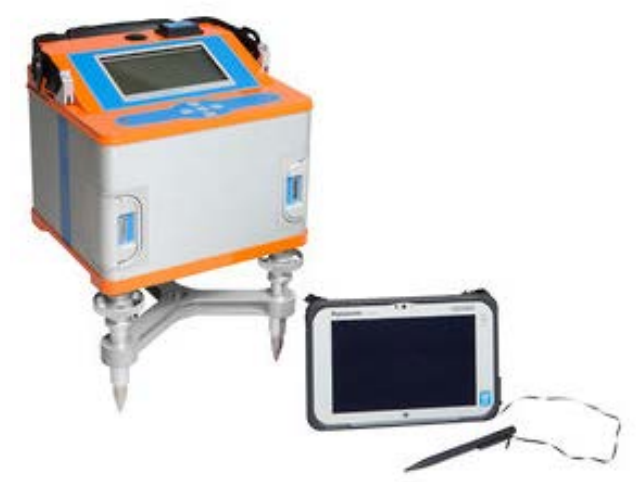

Figura 5 - Gravímetro CG-6 (http://www.scintrexltd.com).

\section{Gravimetria satelital}

\section{LAGEOS - LAser GEOdynamics Satellite}

Em 1976, surge o primeiro satélite voltado para estudos geodinâmicos da Terra. Desenvolvido pela NASA, o LAGEOS iniciou a era dos satélites gravitacionais. Um segundo satélite, o LAGEOS-2, foi fabricado pela Agência Espacial Italiana e lançado em 1992. Estes dois satélites foram construídos especificamente para serem usados pelo sistema SLR (Satellite Laser
Ranging) e, curiosamente, não possuem instrumentos a bordo, têm apenas um conjunto de 426 refletores (Figura 6) instalados numa esfera metálica de sessenta centímetros de diâmetro. Dentre as aplicações divulgadas pelos fabricantes, destacam-se as seguintes: determinar com exatidão a forma do planeta, proporcionar a correta posição do satélite com relação à Terra e monitorar os movimentos das placas tectônicas associados à deriva continental.

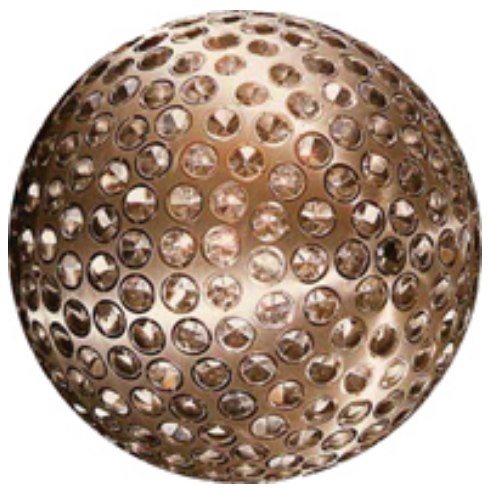

Figura 6 - LAGEOS 1 (http://mix.msfc.nasa.gov/IMAGES/HIGH/7667283.jpg).

CHAMP - CHAllenging Minisatellite Payload

Em meados do ano 2000 surgia a primeira das chamadas novas missões gravimétricas espaciais, dando início à década internacional dos geopotenciais, considerada pela comunidade científica como sendo o marco fundamental para um detalhamento sem precedentes do campo gravitacional terrestre (Lobianco, 2005). Segundo a mesma autora, a grande vantagem dos dados advindos exclusivamente desses satélites fica por conta da homogeneidade dos mesmos, evitando soluções deterioradas por informações terrestres 
imprecisas ou inacuradas.

A CHAMP foi uma missão satelital de origem alemã para pesquisa atmosférica e geocientífica. Teve como objetivo o reconhecimento do campo de gravidade da Terra (geoide) e do campo magnético, bem como investigações do campo elétrico. Durante cinco anos, a partir de seu lançamento, em julho de 2000, a missão esteve em órbita a uma altitude inicial de $454 \mathrm{~km}$. Com o decorrer da missão, visando à realização de estudos mais densos sobre o campo de gravidade, a altitude foi sendo diminuída para $300 \mathrm{~km}$ (Lobianco, 2005).

A missão viabilizou inovadoras medições simultâneas de alta precisão do campo magnético e gravitacional da Terra, uma importante evolução das pesquisas de geopotencial. Paralelamente, deu origem a um modelo do campo gravitacional global, ou Modelo Global do Geopotencial (MGG), quatro vezes mais preciso do que os anteriores, a partir de poucos meses de observação. O primeiro desses foi nomeado de EIGEN-2 (Reigber et al., 2003), e foi desenvolvido em termos de série de funções harmônicas esféricas até grau e ordem 120. A figura 7 apresenta o modelo do geopotencial EIGEN-03S, retratando ondulações geoidais após 33 meses de dados.

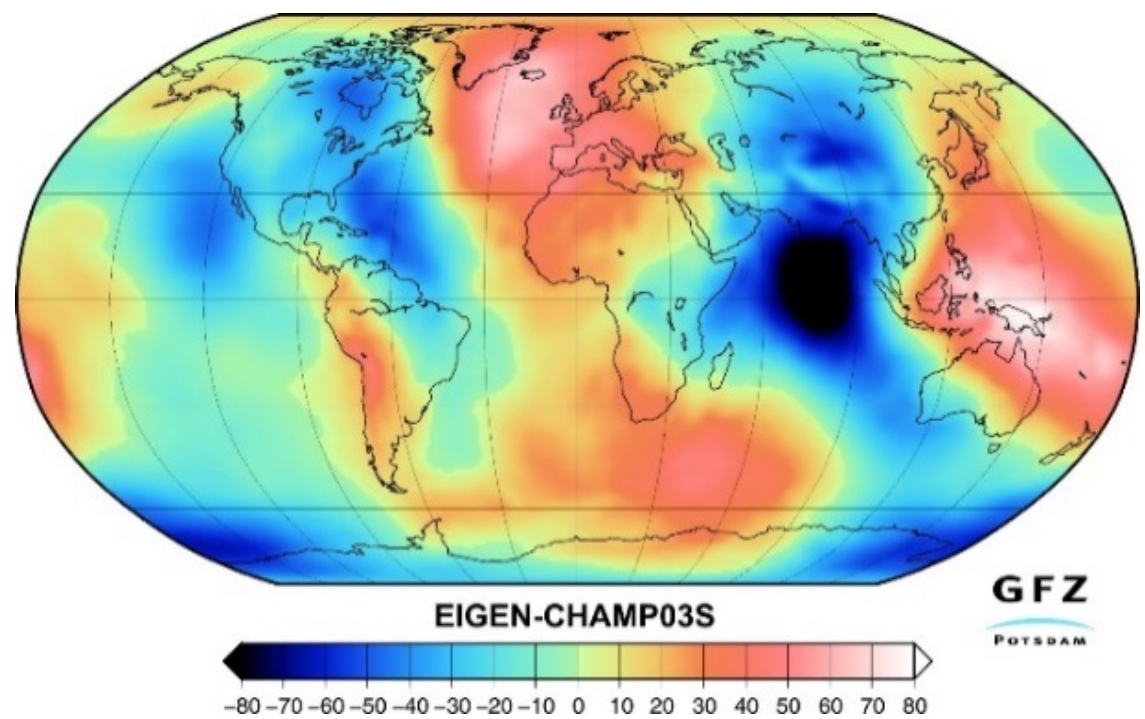

Figura 7 - Modelo EIGEN-03S (metros) (GFZ, 2015).

Além disso, se tornou uma missão piloto para o uso pré-operacional das observações espaciais de GPS para pesquisa atmosférica e ionosférica, bem como para aplicações em monitoramento e previsão climática (GFZ, 2015).

Foi a primeira vez que um satélite em baixa altitude de órbita contou com receptores GPS, permitindo que o seu posicionamento ocorresse satélite-a-satélite, com a precisão de poucos centímetros (Schwintzer \& Reigber, 2002). Esses sinais GPS possibilitaram o monitoramento continuado das perturbações da órbita do satélite. Imagens do satélite e do princípio considerado no posicionamento estão disponíveis na figura 8. A missão teve fim no dia 09 de setembro de 2010.

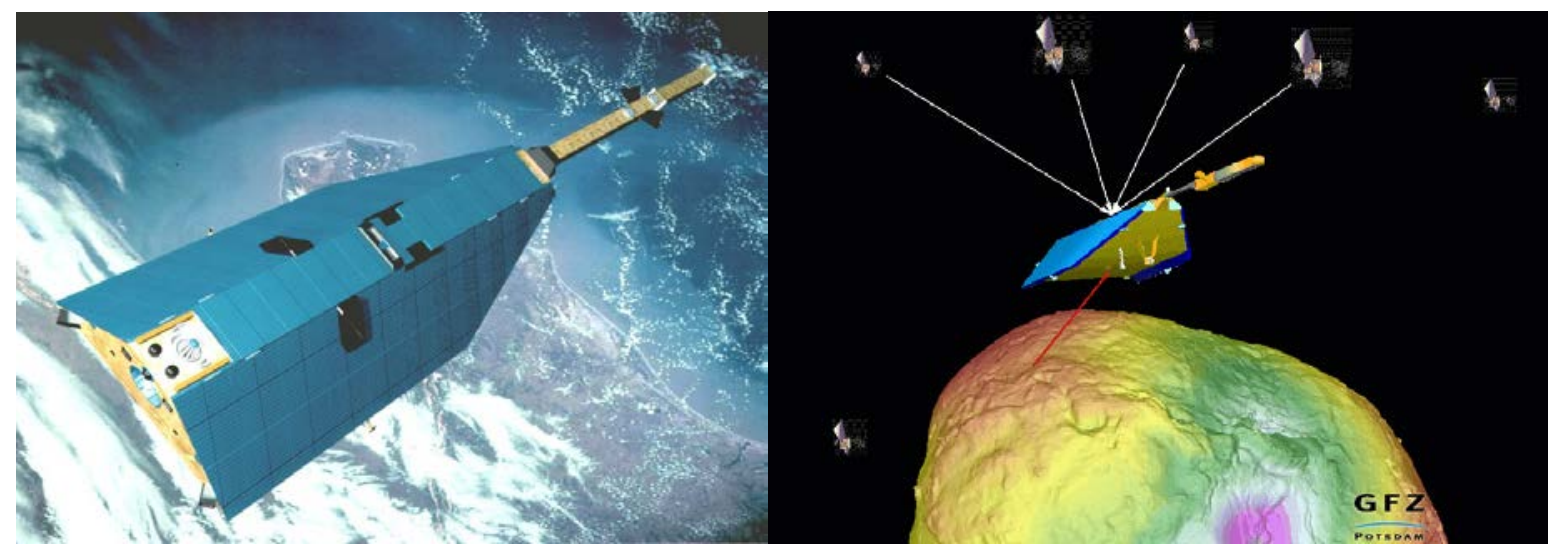

Figura 8 - Imagens ilustrativas do satélite CHAMP e do posicionamento satélite-a-satélite (http://op.gfz-potsdam.de/champ). 


\section{GRACE - Gravity Recovery And Climate Experiment}

Em 2002, é lançada a segunda das modernas missões gravimétricas espaciais, decorrente de uma parceria entre a NASA e o Deutsches Zentrum für Luft und Raumfahrt (DLR) da Alemanha. A missão GRACE, composta de dois satélites gêmeos numa órbita inicial de aproximadamente $500 \mathrm{~km}$ de altitude, foi desenvolvida visando o estudo das variações temporais do campo gravitacional da Terra advindas da distribuição de massas sazonais, anuais e de longo período entre a atmosfera, hidrosfera e criosfera do planeta (Schwintzer \& Reigber, 2002).

Além dos aspectos gravitacionais, GRACE foi também responsável por examinar como a atmosfera afeta os sinais do Global Positioning System (GPS). Pretendia-se à época que a missão melhorasse dados geocientíficos priorizando a Geodésia, Glaciologia, Hidrologia e Oceanografia. Após a fase inicial da missão, o primeiro MGG publicado, com base em análises preliminares de dados obtidos, já apresentou resultados de 10 a 50 vezes mais precisos do que qualquer outro modelo gravitacional anterior que atuasse em faixas médias ou longas de comprimento de onda.

Essa combinação de dois satélites enviados simultaneamente ao espaço foi uma importante evolução em relação à missão CHAMP e todas as demais anteriores, uma vez que novos dados foram obtidos a partir das variações de velocidade e, consequentemente, de aceleração entre os dois satélites. Tais variações ocorrem de maneira sutil, devido principalmente às alterações da configuração física da superfície do planeta. Uma vez sobre os oceanos, ambos os satélites mantêm uma distância pratica- mente constante entre si, cerca de $220 \mathrm{~km}$. Ao entrar numa região sobre maior volume ou densidade de massa, o satélite que viaja à frente sofre um sutil aumento de sua velocidade, que pode ser mensurado pelo satélite que o segue e que sofre as mesmas oscilações de aceleração, mas com algum atraso. Da mesma forma, a velocidade é sutilmente reduzida ao sobrevoar regiões de menor densidade.

Os acelerômetros, equipamentos de alta precisão localizados no centro de massa de cada um dos satélites, são responsáveis por identificar variações de aceleração não gravitacionais, como as que ocorrem devido a eventos atmosféricos. Desta forma, os dados da missão são filtrados, considerando apenas efeitos de causa gravitacional. Atualmente, medições de tais variações ocorrem através da emissão de micro-ondas entre ambos os satélites. Espera-se que, futuramente, seja possível aumentar a precisão de tais medições com o uso de tecnologia a laser. Das três missões que compõem essa nova era espacial, a GRACE é a única que ainda perdura e segue contribuindo com a comunidade científica mundial. A missão GRACE terá sequência com o lançamento do satélite GRACE-FO (Follow-On), lançado em 22 de maio de 2018. Os dois satélites gêmeos estarão separados em 220 km. A missão terá como objetivo rastrear o movimento da água da Terra para monitorar as mudanças no armazenamento de água subterrânea, o monitoramento de quantidade de água em grandes lagos e rios, umidade do solo, gelo e geleiras, além do nível do mar causado pela adição de água ao oceano (JPL, 2017). Imagens dos satélites GRACE são apresentadas na Figura 9.

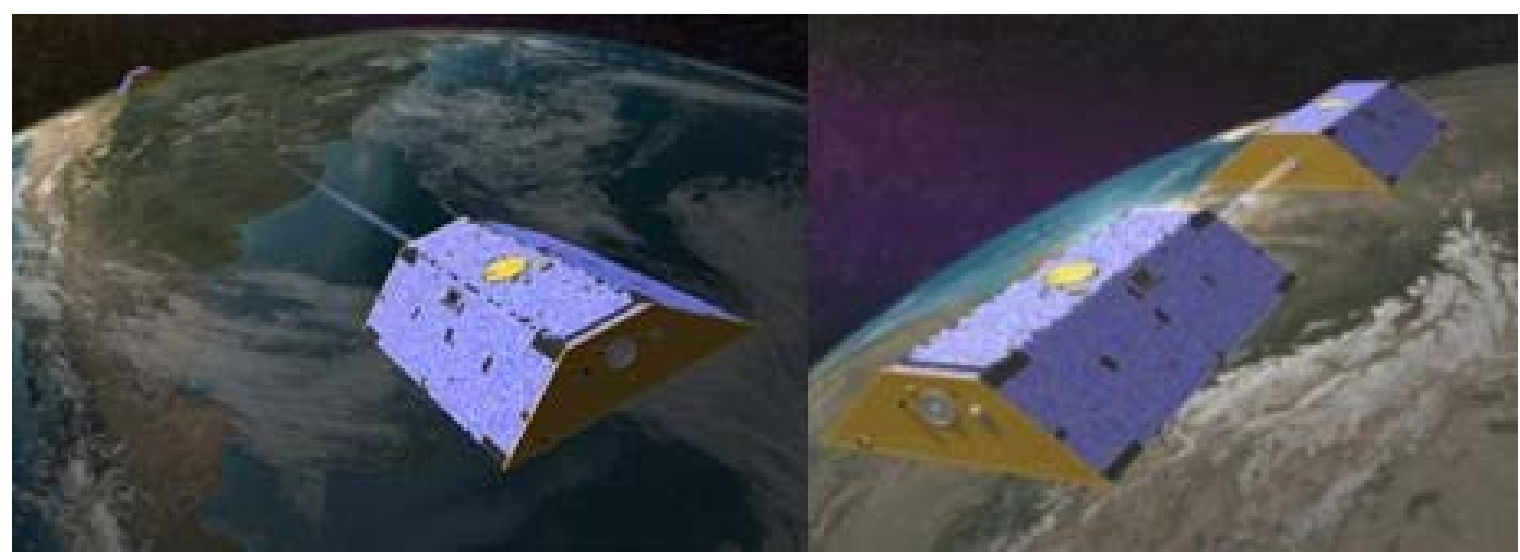

Figura 9 - Imagens do satélite GRACE (http://www.nasa.gov/mission_pages/Grace/multimedia/gallery). 


\section{OCE - Gravity field and steady-state Ocean Circulation Explorer}

A terceira e última das novas missões espaciais foi idealizada pelo European Space Operations Centre (ESA). Alçada ao espaço no ano de 2009, a missão GOCE objetivava analisar as variações do campo gravitacional da Terra com precisão, em termos de ondulação geoidal $\sim 1-2$ cm e distúrbio da gravidade $1-2 \mathrm{mGal}$, para uma resolução melhor que $100 \mathrm{~km}$. Além dessas medições referentes à gravidade, iria explorar aspectos sobre a circulação das massas oceânicas. De fato, ao utilizarem os dados da missão combinados com dados de altimetria, cientistas foram capazes de produzir o MGG mais preciso já feito sobre as correntes oceânicas (ESA, 2015).

Os idealizadores do projeto pretendiam que 0 satélite estivesse em órbita com a menor altitude possível a fim de captar com maior intensidade os sinais do campo gravitacional. Atingiu-se, portanto, uma altura inicial aproximada de 260 $\mathrm{km}$, que foi reduzida durante o último ano da missão para algo em torno de $235 \mathrm{~km}$.

O principal instrumento da missão GOCE, o Electrostatic Gravity Gradiometer, consistia num conjunto de acelerômetros de três eixos, montados numa estrutura extremamente estável. Até então, esse gradiômetro chegava a ser 100 vezes mais sensível que qualquer outro sensor do mesmo tipo que tenha sido enviado ao espaço. Assim como ocorreu com seus dois antecessores CHAMP e GRACE, o satélite contava ainda com um receptor de sinal GPS, utilizado como instrumento de rastreamento posicional, além de um retro-refletor que permitia monitorar com precisão a órbita do satélite por meio do SLR (ESA, 2015). A missão GOCE pode representar os MGGs desenvolvidos em séries de funções harmônicas esféricas até grau e ordem 250-300. Cabe destacar que um MGG é um conjunto de coeficientes da função potencial gravitacional da Terra desenvolvida em série de funções harmônicas esféricas. Diversos MGGs têm sido disponibilizados para a comunidade; alguns desses modelos utilizam informações derivadas das missões LAGEOS, GRACE e GOCE, tais como: EIGEN-6S4(v2) (Förste \& Bruinsma, 2016), EIGEN-6C4 (Förste et al., 2014) e GO_CONS_GCF_2_DIR_R5 (Bruinsma, et al., 2013). Isso ocorre porque, cada uma das missões possui uma contribuição específica em termos de coeficientes da função potencial que retrata as heterogeneidades do planeta Terra. As informações advindas do LAGEOS contribuem para os baixos graus da função potencial (exemplo: o coeficiente $\mathrm{C}_{2,0}$ modela a Terra em termos de achatamento). Os dados da missão GRACE são utilizados para modelar a forma da Terra no que diz respeito aos médios graus (até grau e ordem 70-90). Por fim, as informações do GOCE modelam o planeta para os graus mais altos (até 250) (ICGEM, 2017). Fotos ilustrativas do satélite e do MGG disponibilizado pelo GOCE, retratando a forma da Terra, podem ser visualizadas através da figura 10.

Enquanto esteve em órbita, GOCE forneceu importantes dados para o entendimento da circulação das correntes oceânicas, das variações de nível dos mares, bem como da dinâmica das geleiras e do interior do planeta Terra. Além disso, a missão informou sobre a densidade do ar e velocidade dos ventos na alta atmosfera. Inicialmente, era esperado que o satélite da missão GOCE permanecesse durante 20 meses em órbita, mas em novembro de 2013 o satélite chegou a seu fim natural devido à falta de combustível, estendendo o tempo de execução da missão há pouco menos do que cinco anos (ESA, 2015).
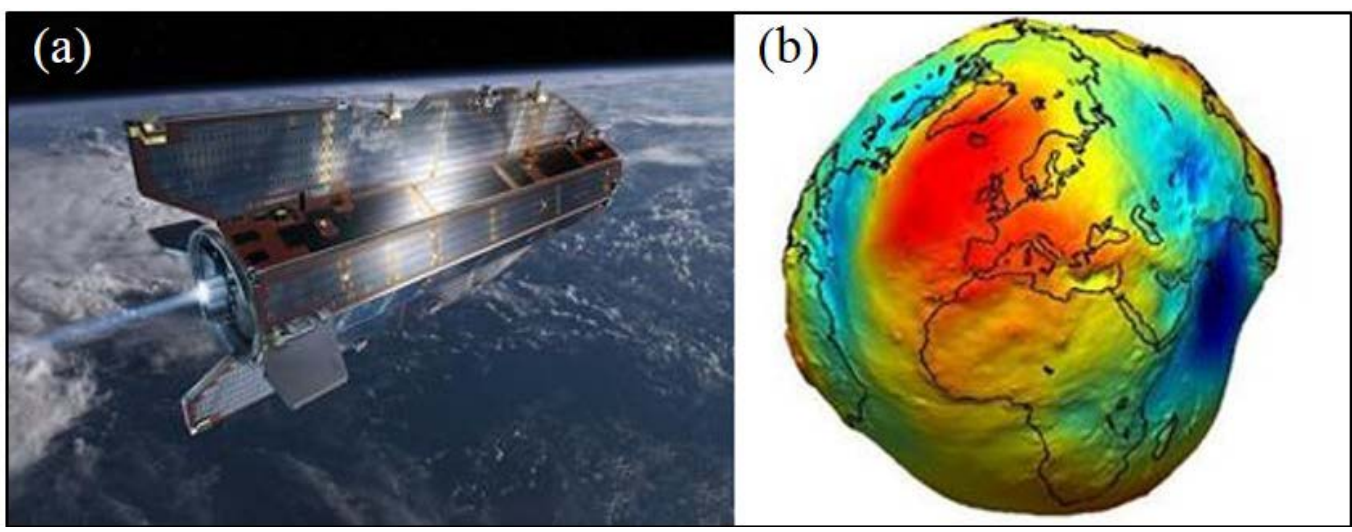

Figura 10 - Satélite (a) e Geoide (b) inerentes à missão GOCE. (http://www.esa.int/spaceinimages/Images). 


\section{Gravimetria aérea e marinha}

No início do século XIX, um grupo de pesquisadores do Instituto de Geodésia de Potsdam realizaram medições da gravidade a bordo de navios nos oceanos Índico, Pacífico e Atlântico. Ao estudar os resultados obtidos, o físico húngaro, Loránd Eötvös, observou diferentes padrões nas medições: ao mover-se para o oriente, os equipamentos registravam um decréscimo do valor da gravidade quando comparado aos deslocamentos em direção ao ocidente. Surgiu, então, o conceito do efeito de Eötvös, que visava à correção dos dados provenientes de medições da gravidade realizadas em movimento e, até hoje, ainda é utilizado em pesquisas de gravimetria marinha e aérea (Persson, 2005).

Durante a segunda guerra mundial, surgem as tecnologias aerogeofísicas para a detecção aérea de submarinos (Hildenbrand, 2002). Anteriormente, utilizavam-se para esta função sistemas aeromagnéticos; na década de 1950, iniciam-se os testes de aerogravimetria, com os gravímetros air-sea L \& R, mas sem resultados satisfatórios. Desde 1955, os gravímetros airsea, produzidos em parceria por Lucien LaCoste e Arnold Romberg, eram utilizados em submarinos. A gravimetria marinha, assim como a aérea, encontrava como maior desafio a neutralização das variações de aceleração produzidas pelo meio de transporte do equipamento. Aos efeitos resultantes do movimento da Terra, seriam somados, portanto, o movimento do sistema de medição em relação à superfície.

Em 1965, foi vendido o primeiro gravímetro L\&R com plataforma estabilizadora. Na década de 1970, as plataformas estabilizadoras triaxiais foram desenvolvidas para o ambiente gravimétrico. Nos anos seguintes, encontraramse maneiras de reduzir a influência das acelerações produzidas pela locomoção dos sistemas de medição. Tanto no domínio oceânico quanto no aéreo, as tecnologias gravimétricas passaram por diversos ciclos de evolução, culminando com o emprego da eletrônica digital, a partir dos anos de 1970, e da utilização dos sinais de satélite do sistema GPS, no final da década de 1980 . No início dos anos 2000, surgem em países de tradição na exploração de recursos minerais, como Canadá e Austrália, novas tecnologias aerogeofísicas na área de aerogravimetria gradiométrica (Hildenbrand, 2002).

Como exemplos de equipamentos utilizados no Brasil há dois sistemas de medição de gravidade fabricados pela principal empresa de tecnologia aeroespacial, a Lockheed Martin, sediada nos Estados Unidos. São eles os sistemas AGG Falcon (Airborne Gravity Gradiometer Falcon), utilizado em aeronaves, e 3D-FTG (Full Tensor Gravity Gradiometer), visualizado na figura 11, utilizado tanto em aeronaves quanto em navios (Galbiatti et al, 2011).

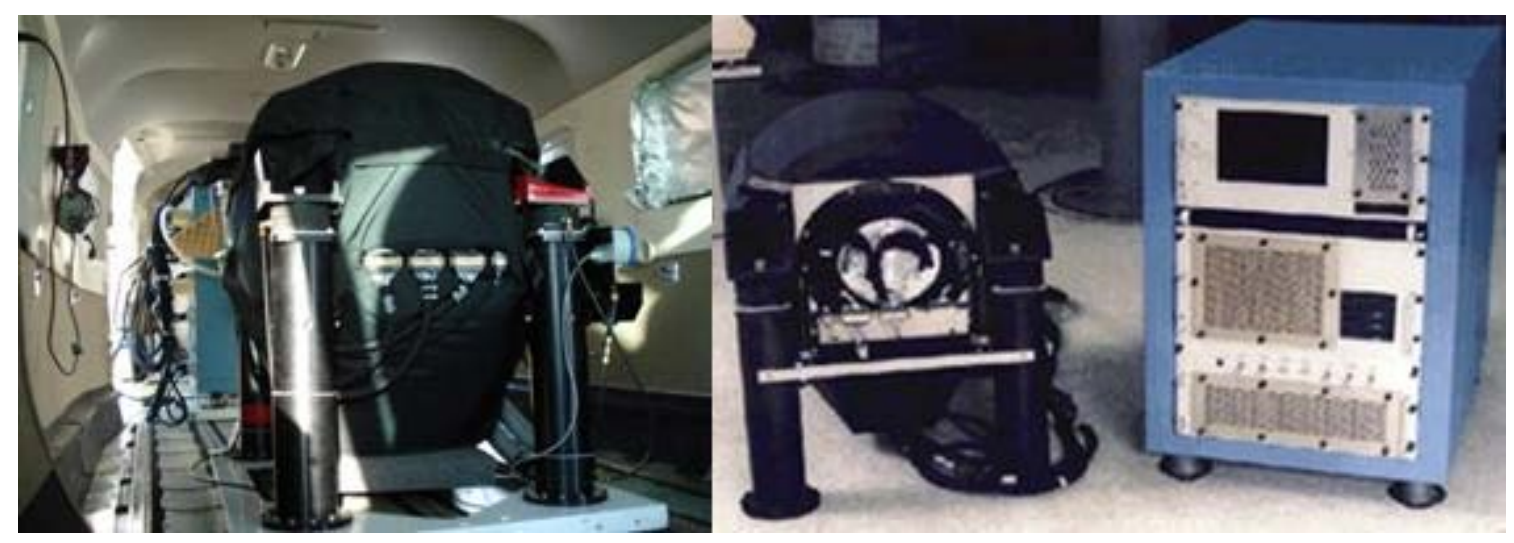

Figura 11 - Sistema 3D - FTG (Galbiatti, 2011).

Esses dois sistemas são tecnologias de plataforma móvel, com múltiplos acelerômetros que medem os gradientes da gravidade. Além disso, utilizam o monitoramento dos ruídos e vibrações sofridas pelo meio de locomoção, através de acelerômetros externos, a fim de realizar posterior compensação dos dados
(Galbiatti et al, 2011).

Embora as pesquisas de gravimetria em ambiente oceânico e aéreo encontrem diversas dificuldades quanto à estabilização do sistema e à compensação de ruídos, estas possuem a vantagem de possibilitar medições de menores comprimentos de onda quando comparadas aos 
dados provenientes de satélites, ou, ainda, de tornarem viáveis estudos em territórios onde o percurso por terra seria de extrema dificuldade, como no caso da floresta amazônica.No Brasil, o primeiro levantamento aerogeofísico se deu em 1952, sob os auspícios do então Conselho Nacional de Petróleo (CNP), na Bacia Sedimentar do Paraná, região de Botucatu, e foi executado pela LASA - Levantamentos Aerofotogramétricos S.A. (CPRM, 2015). Nos dias atuais, a Amazônia ainda representa um grande desafio, não somente pela dificuldade de exploração por terra, mas também por ser extremamente carente de levantamentos aerogeofísicos (Rigoti et al., 2000). Encontra-se na aerogravimetria uma alternativa eficaz e de custo favorável para a detecção de estruturas regionais, algo que poderia levar ao conhecimento aprofundado das bacias sedimentares e escudos antigos da região amazônica, identificando áreas mais favoráveis à exploração mineral (Rigoti et al., 2000). Atualmente, o Banco Nacional de Dados Gravimétricos (BNDG), disponibiliza grande parte do acervo aerogravimétrico empreendido em terras brasileiras, visualizado através do cartograma constante na figura 12 .

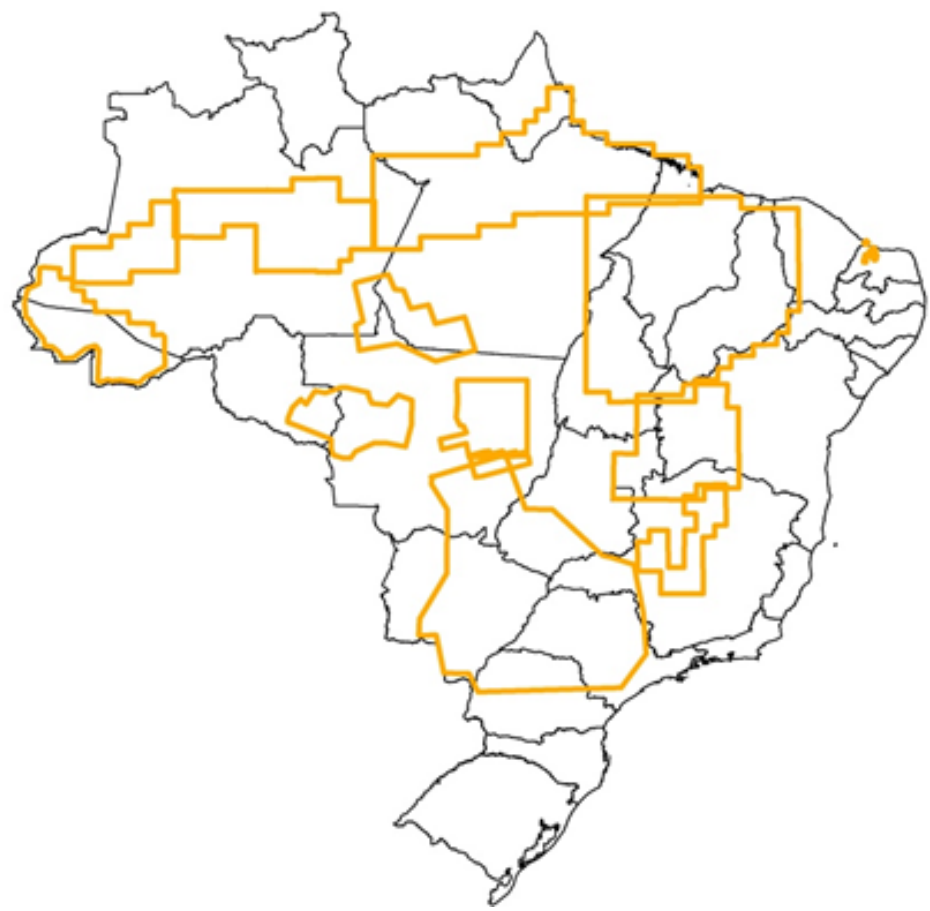

Figura 12 - Acervo de aerogravimetria no BNDG (ANP, 2015).

As variações do campo de gravidade estão diretamente relacionadas às propriedades físicas e estruturais do interior da Terra. Resultados advindos da gravimetria marinha permitem obter diversas informações sobre o relevo e estrutura interna do assoalho oceânico. Tais resultados, associados às medições de altimetria por radar e sonar, do relevo oceânico, servem para investigar a estrutura da tectônica global e das margens dos continentes (Fairhead et al., 2001).

$\mathrm{O}$ uso de um radar em órbita permite medir com precisão a topografia dos oceanos, que é aproximadamente uma superfície equipotencial (Sandwell et al., 2014). Nesse sentido, oito missões de radar de alta precisão ocorreram eapoiaram as atividades gravimétricas marinhas: Geosat: 1985 a 1989; ERS-1: 1991 a 1998; Topex/Poseidon: 1992 a 2006; ERS-2: 1995 aos dias atuais; GFO: 1998 aos dias atuais; Jason 1:
2001 aos dias atuais; ENVISAT: 2002 aos dias atuais, Jason 2: 2008 aos dias atuais, Jason 3: 2016 aos dias atuais.

Embora seja bastante esparsa, a cobertura gravimétrica dos navios sobre os oceanos é importante ferramenta para o mapeamento de estruturas tectônicas, especialmente bacias oceânicas profundas. Estas geralmente possuem espessa camada de sedimentos que chega a se estender por muitos quilômetros em direção à litosfera e contribuem para encobrir as características originais do relevo (Sandwell et al., 2014). Assim como a gravimetria aérea, as medições marinhas resultam em dados sempre passíveis de ajuste (Paolo, 2009). Diversos empecilhos podem ocorrer durante a obtenção de dados gravimétricos marinhos, acarretando a necessidade de cuidados ou ajustes voltados à sensibilidade do equipamento de medição e seu 
nivelamento, ao equacionamento de problemas ligados ao posicionamento dos navios, à deriva instrumental e à falta de estações de referência para abertura e fechamento das linhas. Imagem de um gravímetro Microg Lacoste, modelo TAGS-6 Dynamic pode ser vista na figura 13.

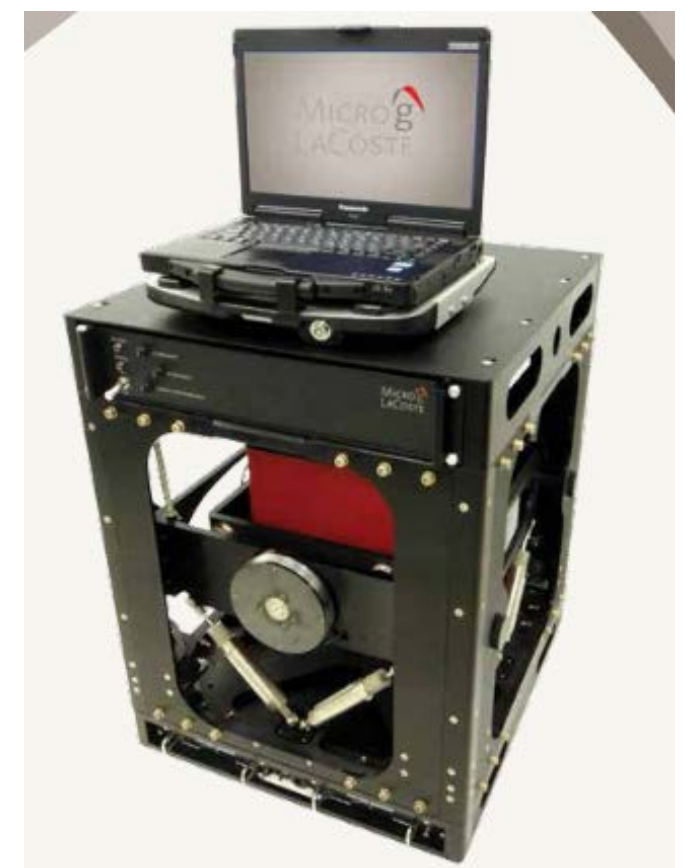

Figura 13 - Gravímetro marinho L\&R (http://www.cgg.com).

Trazendo a questão à esfera nacional, a Marinha Brasileira, por meio da Diretoria de Hidrografia e Navegação (DHN), coordena as atividades do Grupo de Trabalho para Acompanhamento da Proposta do Limite Exterior da Plataforma Continental Brasileira (GT LEPLAC), instituído pela portaria $\mathrm{N}^{\circ}$ 330/MB, de 15 de dezembro de 2005. O LEPLAC é um programa do Governo Brasileiro e faz parte do projeto da Comissão Interministerial para os Recursos do Mar (CIRM), que estabelecerá o limite exterior da plataforma continental da Zona Econômica Exclusiva (ZEE), além das 200 milhas, com base na aplicação dos critérios do artigo 76, da Convenção das Nações Unidas sobre o Direito do Mar (CNUDM).

No âmbito desse projeto foram considerados conceitos geodésicos, hidrográficos, geológicos e geofísicos, cuja aquisição de dados contou com a participação da Petrobras, de Universidades e de diversos navios hidrográficos e oceanográficos da DHN.

A primeira etapa de levantamentos produziu mais de 92 mil quilômetros de perfis gravimétricos. Foi conduzida entre os anos de 1987 e 2005, ao longo da margem continental, do Oiapoque ao Chuí, até uma distância do litoral de aproximadamente 350 milhas.

Uma nova série de levantamentos geológicos, geofísicos e hidrográficos ao longo da margem brasileira se fez necessária, a fim de respaldar uma proposta revisada, enfocando aspectos técnicos e pontos discordantes das recomendações da Comissão de Limites da Plataforma Continental (CLPC), das Nações Unidas, que não aceitou integralmente o pleito inicial encaminhado pelo GT LEPLAC. Nesse novo período, mais de 81 mil quilômetros de perfis gravimétricos foram levantados (Marinha do Brasil, 2015).

Com base no exposto, depreende-se que o Brasil possui grande quantidade de dados referentes aos levantamentos gravimétricos marítimos efetuados em sua costa. O primeiro acervo, mostrado no cartograma inserido na figura $14 \mathrm{a}$, está disponibilizado no BNDG. O outro grande banco de dados, apresentado nos mapas constantes da figura $14 \mathrm{~b}$, sintetiza as aquisições gravimétricas, batimétricas, sísmicas e magnetométricas, auferidas nos dois grandes esforços empreendidos pelo LEPLAC.

Mesmo que não estejam espacialmente localizadas sobre a terra firme, todas essas informações, agregadas aos dados gravimétricos aéreos, terrestres e satelitais podem ser aproveitadas para fins geodésicos, 
sobretudo na elaboração de modelos geoidais, uma vez que a metodologia empregada no MAPGEO2015, por exemplo, considera uma faixa adicional de aproximadamente 100 quilômetros no entorno da região continental efetivamente modelada.

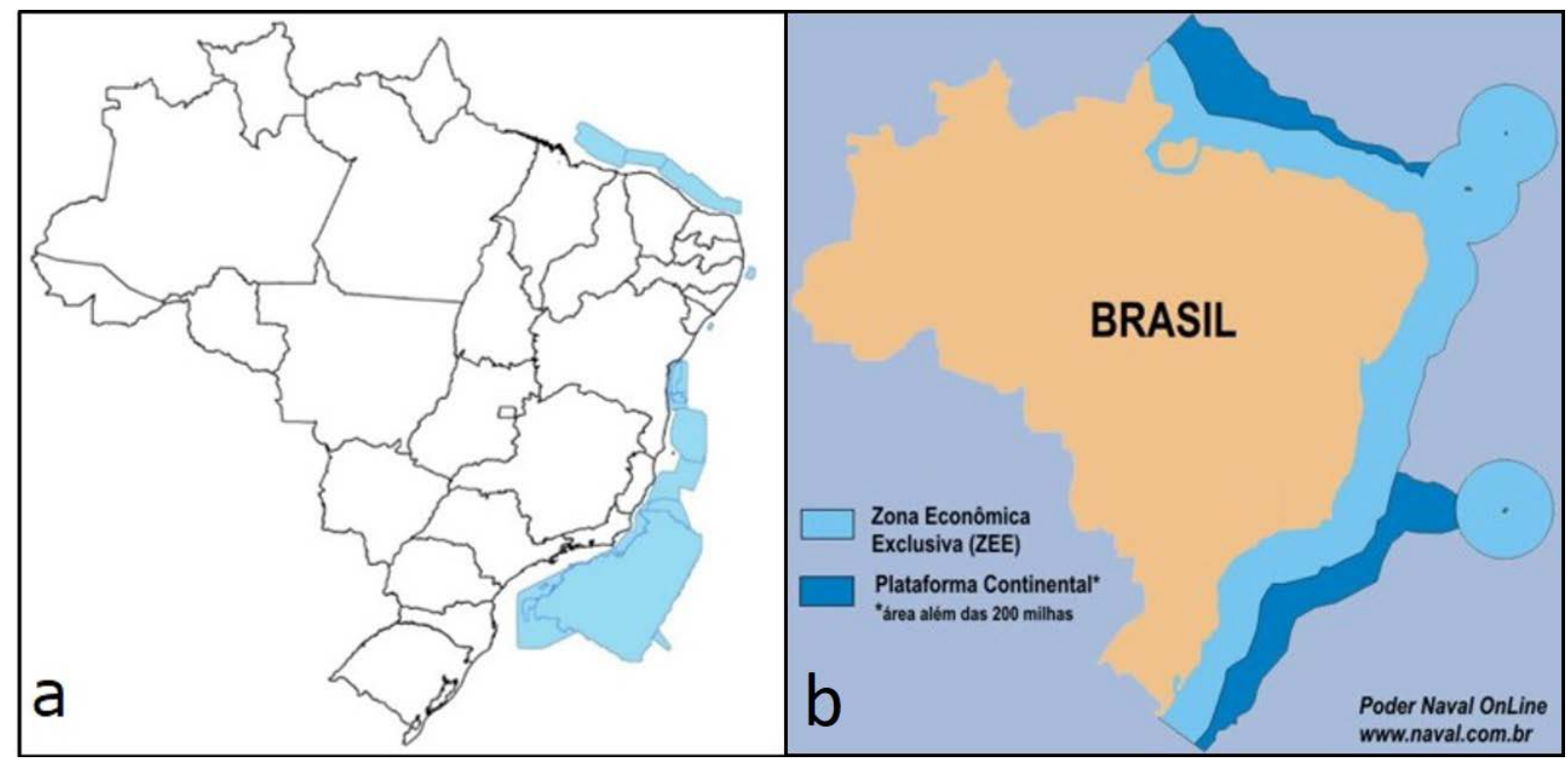

Figura 14 - Dados de gravimetria marinha constantes no BNDG (ANP, 2015) (a) acervo LEPLAC (MB/LEPLAC, 2015) (b).

\section{PRINCIPAIS INSTITUIÇÕES BRASILEIRAS PRODUTORAS DE GRAVIMETRIA}

Decorridos mais de três séculos após a primeira determinação gravimétrica no Brasil, ainda não há uma instituição que se incumba da gestão das atividades gravimétricas em âmbito federal. Recentemente a Agência Nacional do Petróleo, Gás Natural e Biocombustíveis (ANP), avocou para si a organização do BNDG, que congrega informações da maior parte das instituições produtoras. Entretanto, a lacuna deixada pela ausência de uma coordenação e controle das atividades em território nacional ainda persiste.

Por conta dessa atipicidade, advinda de uma ausência de gerenciamento, algumas organizações há anos vêm conduzindo seus levantamentos, quase sempre a partir de iniciativas individuais isoladas, visando contemplar seus propósitos institucionais. Analogamente, universidades com disciplinas em Geofísica ou Geodésia, executam seus afazeres gravimétricos voltados aos fins acadêmicos. Em síntese, por mais que haja convergência dos objetivos, esforços são duplicados e os dados nem sempre compartilhados.

Atendendo ao escopo deste artigo, serão tecidas considerações sobre a atuação das principais entidades que produzem gravimetria no país, enfatizando-se aquelas que atendem às metas geodésicas que, por conseguinte, possibilitam ganhos ambientais. Os critérios adotados nesta priorização dizem respeito ao volume e abrangência dos dados produzidos. Algumas universidades deixaram de ser esmiuçadas devido à estrita vinculação aos objetivos acadêmicos concernentes com as atividades geofísicas, fugindo, portanto, aos propósitos do artigo.

\section{Observatório Nacional (ON)}

A instituição brasileira pioneira nas atividades gravimétricas é o ON. Em outubro de 1851 foram empreendidas medições com o pêndulo de Foucault. Posteriormente, nos primeiros anos do século $\mathrm{XX}$, novas medições foram realizadas, utilizando-se um dispositivo tetrapendular de Sterneck. Em 1948, foram efetuadas determinações com um pêndulo Brown (ON, 2015).

Nos anos subsequentes, diversas determinações foram conduzidas pelo Grupo Woollard, contemplando a mesma estação, localizada na atual Sede do $\mathrm{ON}$, com valores absolutos e vinculando-a ao sistema mundial existente à época. Em decorrência dessas determinações, a citada estação do $\mathrm{ON}$ chegou a ser considerada como sendo o datum gravimétrico brasileiro (Castro Junior, 2005).

Em meados do século passado, mais precisamente no ano de 1955, com a aquisição de um gravímetro Worden, houve o início de 
uma nova etapa de atividades gravimétricas sistemáticas.

Em 1967, um primeiro gravímetro L \& G, modelo $G$, foi cedido pelo Inter American Geodetic Survey (IAGS) e passou a operar em substituição ao antigo Worden.

Atendendo a uma recomendação das comunidades científica e usuária, em 1978 o ON passou a ser responsável pela implantação e manutenção da Rede Gravimétrica Fundamental Brasileira (RGFB) (Figura 15), que atualmente possui cerca de 620 estações materializadas em vários recantos do território nacional. Em termos gravimétricos essa é a missão mais importante do $\mathrm{ON}$, pois suas informações, disponibilizadas gratuitamente no site institucional, propiciam um arcabouço de referência aos levantamentos conduzidos no Brasil e em países fronteiriços.

Em paralelo à implementação da RGFB, o ON estabeleceu no ano de 1996, uma linha de calibração gravimétrica na região de Itatiaia, estado do Rio de Janeiro. Este circuito é composto por cinco pontos criteriosamente materializados a fim de possibilitar a calibração de gravímetros relativos através da variação altimétrica das estações.

Entre 2010 e 2011 a RGFB foi aquinhoada com novas estações insulares, mais precisamente em Fernando de Noronha e no Arquipélago de São Pedro e São Paulo. Em 2015 foi a vez da Ilha de Trindade. Essas operações contaram com o apoio da Marinha Brasileira (Sousa, 2015).

Reforçando o caráter de pioneirismo no contexto gravimétrico nacional, em 2004 o ON trouxe para o Brasil seu primeiro gravímetro absoluto, um FG5. Dois anos depois chegou o segundo absoluto, um A10. Atualmente, esses equipamentos são utilizados na ocupação de antigas estações da rede de referência relativa, incluindo a linha de calibração de Itatiaia, e na

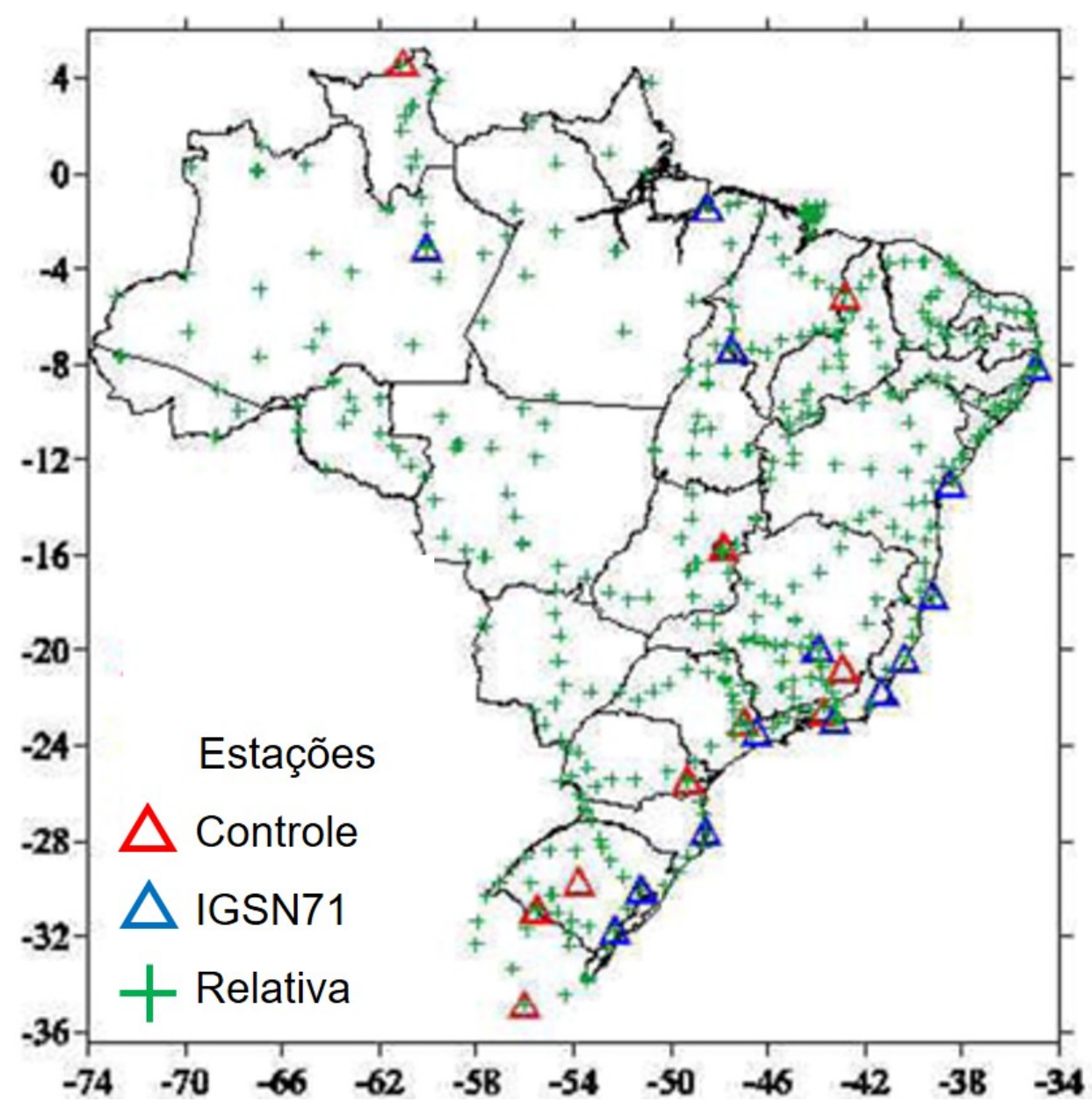

Figura 15 - Rede Gravimétrica Fundamental Brasileira (www.on.br).

implantação de novas estações absolutas, com o intuito maior de densificar e dar mais consistência à RGFB. Além desses dois equipamentos, o ON conta com cinco gravímetros relativos, sendo três L\&R e dois Scintrex CG-5 (ON, 2015). 
Agência Nacional de Petróleo, Gás Natural e Biocombustíveis (ANP)

Por meio do decreto $\mathrm{n}^{\circ}$ 2.455, de 14/01/1998, foi criada a ANP, vinculada ao Ministério de Minas e Energia, com o propósito de ser a instituição reguladora e executora da política brasileira para o setor energético nacional (ANP, 2015).

De imediato a ANP herdou o acervo gravimétrico terrestre que dispunha a Petróleo Brasileiro S.A. (Petrobras), advindo de levantamentos conduzidos ao longo das principais bacias sedimentares do país, por conta da prospecção petrolífera. Adicionalmente, agregou inúmeras informações aerogravimétricas e marítimas, obtidas com a mesma finalidade.

No ano de 2009 a ANP, com o apoio da comunidade científica, tomou a iniciativa de criar o BNDG, contemplando um antigo anseio nacional, com o objetivo maior de consolidar a base gravimétrica nacional, deixando-a prontamente acessível para cumprir as metas geocientíficas que a nação requer (Geofísica Brasil, 2015). Esse imenso acervo de dados, composto incialmente por 80 mil estações gravimétricas, passou a abrigar informações oriundas de diversas entidades públicas, dentre as quais se destacam a Petrobras, Sociedade Brasileira da Geofísica (SBGf), Universidades, Institutos de Pesquisa e o IBGE. Posteriormente serão agregadas informações aerogravimétricas e marítimas.

Segundo dispõe a ANP, o BNDG possui atualmente algo em torno de cem mil estações. Seu conjunto de dados encontra-se disponível através do Banco de Dados de Exploração e Produção (BDEP), também da ANP (Ribamar, 2015). Todo esse acervo pode ser sintetizado e visualizado através do cartograma constante na figura 16.

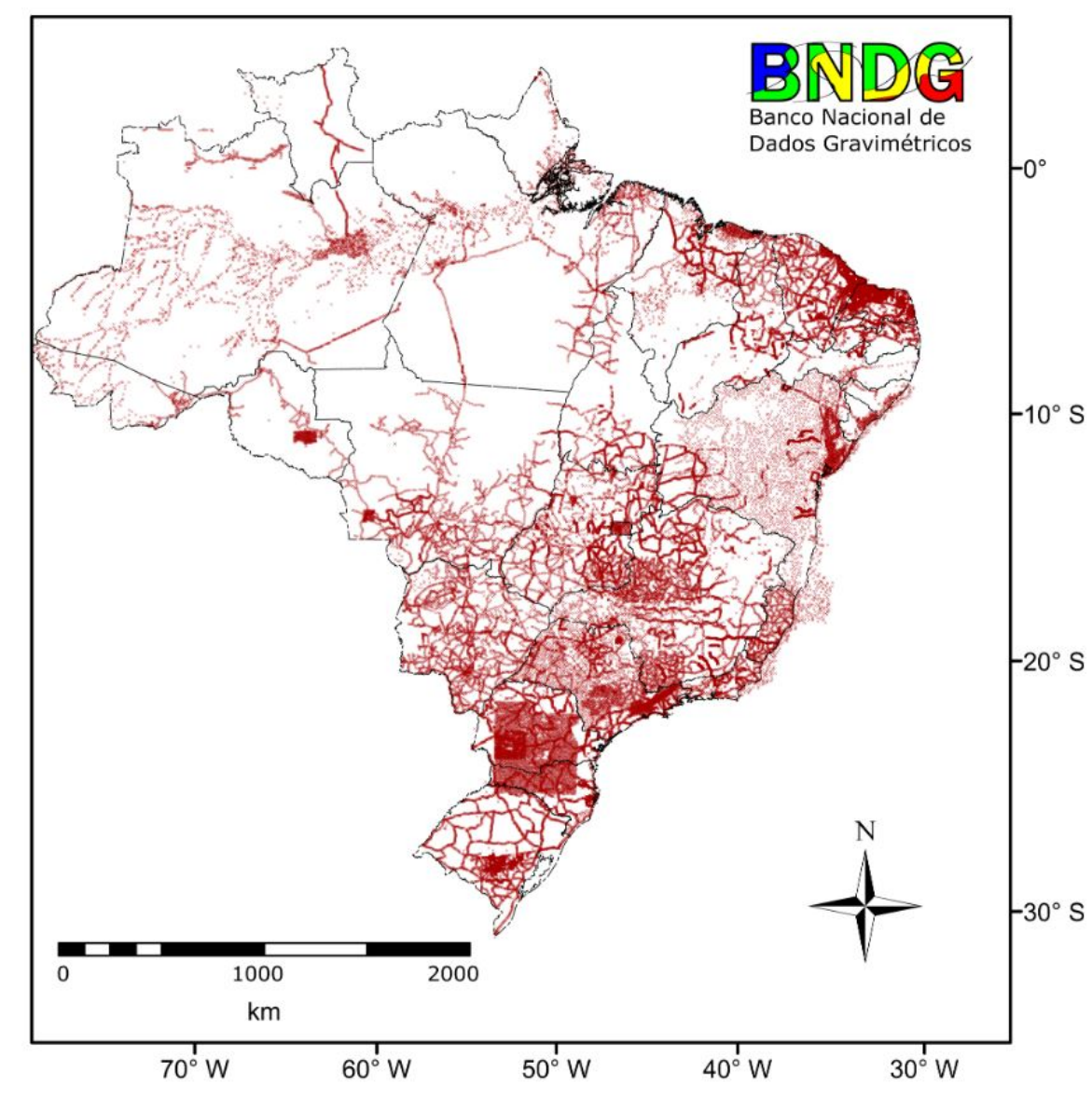

Figura 16 - Acervo do BNDG (http://geofisicabrasil.com, 2015).

\section{Serviço Geológico do Brasil (CPRM)}

Foi no final dos anos 1970, inserido no Projeto Levantamento Gravimétrico do Estado da Bahia, que os primeiros levantamentos terrestres foram executados pela Companhia de Pesquisa de Recursos Minerais (CPRM), utilizando um gravímetro Worden (Gomes \& Mota, 1980). 
Com financiamento do Departamento Nacional de Produção Mineral (DNPM), essa iniciativa teve à frente o Geólogo Nelson Custódio que, na época, era chefe da Superintendência de Salvador (SUREG/SA) da CPRM.

Uma segunda investida só veio a ocorrer em meados dos anos 1980, no contexto do Programa Levantamentos Geológicos Básicos do Brasil (PLGB), tendo como objetivo distinguir estruturas e corpos geológicos no auxílio ao mapeamento geológico.

Tais levantamentos foram conduzidos mediante um convênio entre a CPRM e o ON. Os poucos levantamentos gravimétricos que ocorreram na década de 1990 ficaram por conta de trabalhos de pós-graduação e de levantamentos direcionados às pesquisas hidrogeológicas em pequenas bacias interiores da Região Nordeste (Pinto, 2015).

A partir de 2003, já com a denominação de Serviço Geológico do Brasil, a CPRM deu início à renovação de seus equipamentos e adquiriu quatro gravímetros Scintrex CG-5.

Entretanto, a produção gravimétrica só foi retomada em 2011 e, desde então, já foram determinadas cerca de 5900 estações gravimétricas terrestres em diversas áreas do Brasil, voltadas à pesquisa mineral e estudos tectônicos.

Em 2013 foi adquirido um aerolevantamento gravimétrico convencional, com direção de linhas de voo Norte-Sul, espaçamento entre as linhas de $3 \mathrm{~km}$ e altura de voo de $1100 \mathrm{~m}$.

Segundo Pinto (2015), as perspectivas gravimétricas no âmbito da CPRM são crescentes. Dentro dos projetos aprovados para o ano de 2015, estima-se que serão adquiridos cerca de 4.000 a 5.000 novas medidas gravimétricas terrestres.

Em paralelo, novas áreas para a aquisição de dados aerogravimétricos estão planejadas e selecionadas, porém ainda sem previsão de quando serão trabalhadas, pois dependerão dos recursos financeiros disponibilizados pelo governo.

As finalidades dessas aquisições são diversificadas, variando desde objetivos regionais, como o estudo de zonas de sutura entre blocos, até pesquisas gravimétricas localizadas em áreas de requerimento mineral da empresa.

\section{Universidade Federal do Paraná (UFPR)}

As atividades de gravimetria na UFPR tiveram início nos anos 1960, sob a liderança de um ícone da Geodésia no Brasil, o professor Camil Gemael.

Os levantamentos em campo começaram com um gravímetro Worden e contaram com o apoio da Petrobrás. O Estado do Paraná foi o primeiro palco de operações, priorizando-se a capital e municípios vizinhos.

À época tais atividades eram empreendidas no âmbito do Centro de Estudos em Geodésia, até o ano de 1971, quando passou a ser denominado Curso de Pós-Graduação em Ciências Geodésicas (CPGCG), que perdura até os dias atuais contribuindo com informações gravimétricas (Freitas, 2015).

No decorrer daquele mesmo ano de 1971, houve a efetiva participação do CPGCG na implantação da primeira grande rede gravimétrica mundial, a IGSN71, com a medição de duas estações principais e uma auxiliar em Curitiba.

Nos anos seguintes outro trabalho de porte ocorreu na Ilha de Santa Catarina, ainda contando com o mesmo gravímetro Worden.

Em 1976 o L\&R número 372 foi incorporado à UFPR, reforçando quantitativa e qualitativamente os levantamentos subsequentes (Freitas, 2015).

A partir de então, ocorreram novas e significativas contribuições gravimétricas nos estados da região Sul. Destaca-se a Rede Paranaense de Alta Precisão, coincidente com as vinte estações da Rede Estadual implantada pelo IBGE.

Esta rede teve a contribuição de um gravímetro CG-3 (Santos Junior, 2005). Também merece destaque a estação de marés terrestres, implantada em 1985, dedicada ao monitoramento das diferenças de atração lunissolar no centro de massa terrestre e na superfície; esta estação já recebeu mais de quinze gravímetros de diferentes institutos espalhados pelo planeta (Freitas, 2015).

Durante 1989, outro marco pioneiro foi protagonizado pelo CPGCG, ao trazer para o Brasil o gravímetro absoluto Jilag-3, operado por dois profissionais pertencentes à Universidade de Hannover, com o intuito de dar início à Rede Nacional de Estações Gravimétricas Absolutas (RENEGA). Esclarecimentos adicionais sobre a 
RENEGA podem ser obtidos em Torge et al. (1994) e Luz (2008).

Contando com o apoio operacional do IBGE, foram medidas naquele ano as sete primeiras estações da RENEGA nas cidades de Brasília, Curitiba, Santa Maria, Teresina, Vassouras, Viçosa e Vinhedo (Gemael, 1999).

\section{Universidade de São Paulo (USP)}

Quando o assunto é geodesia no âmbito da USP, surge naturalmente o nome do Professor Denizar Blitzkow que, há quarenta anos, vem protagonizando episódios gravimétricos no Brasil e em diversos países mundo afora.

Há duas vertentes na USP que trabalham com gravimetria. A mais antiga e com levantamentos em diversas unidades da federação é o Instituto Astronômico e Geofísico (IAG). Posteriormente, a Escola Politécnica da USP (EPUSP) também passou a se envolver com o tema gravimetria aplicada à engenharia e, sobretudo, à ciência geodésica.

Foi em 1977, com a aquisição de um gravímetro L\&R, quando foram realizadas as primeiras medições de "g” pela USP nos marcos da Rede Altimétrica de Alta Precisão (RAAP). As ideias de se elaborar um primeiro modelo geoidal para o Brasil surgiram naquela ocasião. Durante anos o IAG deu sequência a esses levantamentos e, atualmente, está mais voltado às pesquisas geofísicas com viés acadêmico.

Em 1981 a USP bateu pela primeira vez às portas da antiga Diretoria de Geodésia e Cartografia do IBGE (DGC), solicitando apoio para aprimorar as atividades de gravimetria direcionadas às necessidades geodésicas do Brasil. Nascia naquele momento uma grande e profícua parceria.

No ano de 1991, novos acontecimentos envolvendo a EPUSP motivaram um segundo pedido de ajuda ao IBGE. Foi o advento do projeto Anglo-Brazilian Gravity Project (ABGP) que pretendia ampliar a cobertura gravimétrica dos vazios existentes em terras brasileiras.

Praticamente uma década depois, outra colaboração mais ambiciosa foi requerida, levando o IBGE a atuar fora das fronteiras nacionais. Tratava-se do South American Gravity Studies (SAGS), nova modalidade do ABGP, que estendia o palco de operações aos países vizinhos.

Ambos os projetos contavam com a parceria da Universidade inglesa de Leeds e com apoio de equipamentos e financeiro do então Defense
Mapping Agency (DMA) dos Estados Unidos, hoje denominado National GeospatialIntelligence Agency (NGA) (Castro Junior, 2005).

À parte dos esforços voltados às operações em campo, contribuições acadêmicas importantes para o contexto geodésico brasileiro foram disponibilizadas à sociedade pela equipe da EPUSP. Lobianco (2005), apresentou uma metodologia para sistematizar e calcular alturas geoidais e, a partir daí, versões atualizadas do modelo geoidal brasileiro vem sendo processadas pela USP.

Adicionalmente foram elaborados procedimentos voltados à implementação de um Modelo Digital do Terreno continental (Matos, 2005; Matos \& Blitzkow, 2008), bem como aprimorado o cálculo de modelos geoidais regionais e continentais (Matos et al., 2012).

Em 2016, foi disponibilizada a última versão do modelo geoidal da América do Sul (Blitzkow et al., 2016). Recentemente, em 2013, a EPUSP intermediou a aquisição de um gravímetro absoluto A-10 pelo Governo do Estado de São Paulo.

Em que pese o pouco tempo de uso e a complexidade presente na operação desse equipamento, cerca de uma centena de estações absolutas já foram implantadas, medidas e processadas em território brasileiro, na Argentina, Venezuela e Equador.

Os esforços ao longo de mais de 30 anos, agregado aos acordos de cooperação dos países sul-americanos, culminaram com um conjunto de mais de novecentos mil estações gravimétricas apresentados na figura 17.

\section{Instituto Brasileiro de Geografia e Estatística (IBGE)}

As atividades gravimétricas do IBGE tiveram início em 1956 com a medição de circuitos voltados à calibração de gravímetros. Posteriormente, especial atenção foi dada ao entorno do ponto datum planimétrico, denominado Chuá, na região de Uberaba, Minas Gerais. Foram inúmeros anos dedicados à densificação dos arredores do datum Chuá que, à época, era a estação mais importante do Sistema Geodésico Brasileiro (SGB). Como resultado, mais de 2000 estações foram medidas num raio de trezentos quilômetros ao redor de Chuá, com o objetivo maior de efetuar um detalhamento gravimétrico indispensável ao estabelecimento do SGB (IBGE, 2015). 
Naqueles anos havia considerável dificuldade para se adquirir ou conseguir a cessão de gravímetros. Paralelamente, cabia ao IBGE exercer a sua missão de gestor do SGB, que perdura até os dias atuais, com a necessária inserção da componente gravimétrica no cenário nacional. No início dos anos 1980, esse quadro teve uma oportuna mudança através da primeira aproximação com a USP, mais especificamente com o IAG. Na ocasião discutiu-se sobre um projeto gravimétrico conjunto voltado, em última análise, à elaboração de um pioneiro modelo geoidal brasileiro. Apenas um gravímetro L\&R apoiava tais levantamentos. Essas atividades conjuntas perduraram até 1989, com ênfase nos estados do Mato Grosso do Sul, Mato Grosso e Minas Gerais. Quase uma década depois da primeira investida envolvendo o IBGE e a USP, ocorreu o início de uma segunda etapa, desta vez com a EPUSP. Tratava-se do projeto ABGP - já mencionado neste artigo. Nascia então a parceria mais expressiva envolvendo essas duas instituições em termos gravimétricos; os objetivos eram traduzidos pela desejável melhoria do incipiente modelo geoidal brasileiro.

O marco inicial do ABGP transcorreu em julho de 1991, com a calibração dos quatro gravímetros L\&R disponibilizados ao projeto. Ainda naquele mesmo mês houve os primeiros levantamentos na região central do país. Os anos subsequentes experimentaram intensa atividade e inúmeros vazios gravimétricos existentes em terras brasileiras foram sendo gradativamente preenchidos, priorizando-se as regiões Norte, Centro-Oeste e Nordeste. Destaque merecido deve ser dado às operações na Amazônia, ao longo do Rio Negro e no Pantanal Mato-grossense (Figuras 18a e 18b), sobretudo pela atipicidade de que estas se revestiam (Castro Junior, 2005).

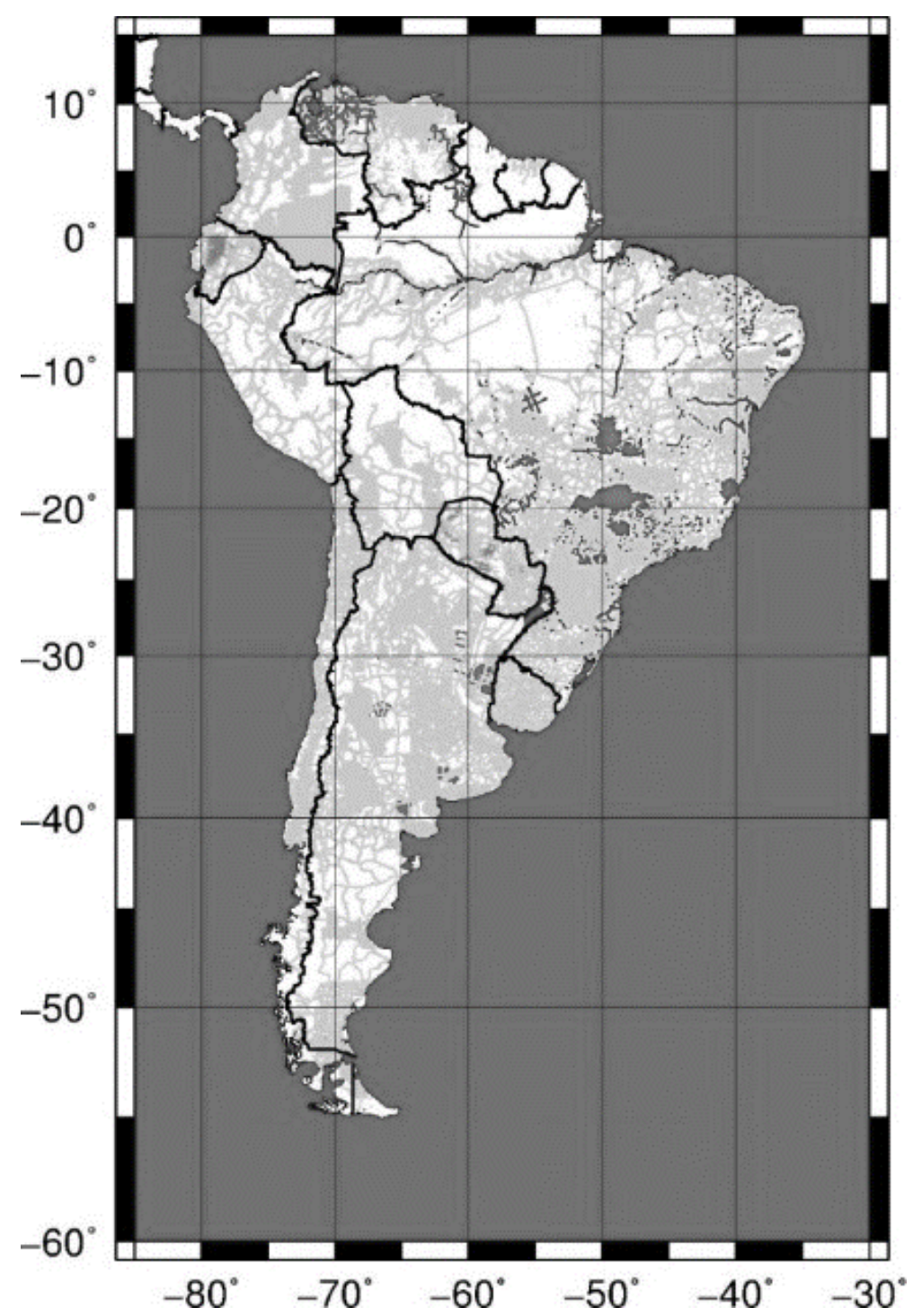

Figura 17 - Estações gravimétricas usadas no modelo geoidal sul-americano (Blitzkow, 2016). 


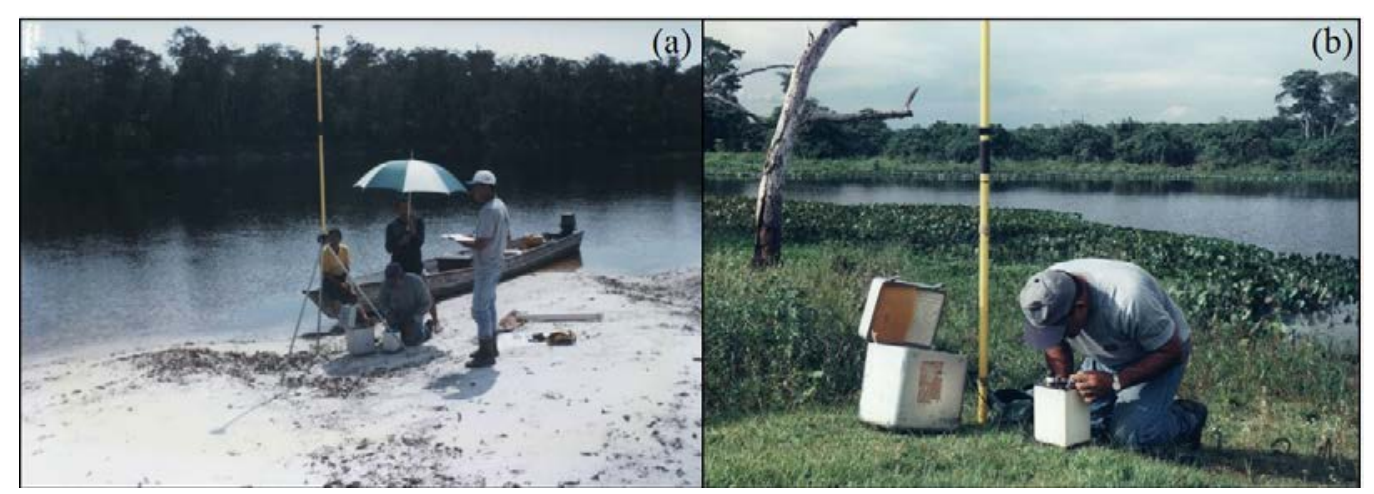

Figura 18 - Gravimetria na Amazônia (a) e no Pantanal (b).

Cerca de uma década depois do início do ABGP, sentiu-se a necessidade de se descortinar novos horizontes ampliando a área de trabalho. As razões dessa expansão foram diversas, porém as principais diziam respeito à elaboração de um modelo geoidal único para a América do Sul e à melhoria dos sucessivos MGGs, elaborados pela National Aeronautics and Space Administration (NASA). Destarte uma nova fase foi iniciada, já com a denominação ABGS, abarcando alguns países sul-americanos carentes de informações gravimétricas. É importante mencionar os ganhos que a Geodésia brasileira auferiu com tais atividades, tendo em vista que a metodologia de cálculo para o modelo geoidal nacional requer informações de regiões que extrapolam as fronteiras brasileiras. Por conta disso, o IBGE passou a atuar também em algumas nações vizinhas, em prol de uma maior homogeneidade de dados no continente. Ainda que menos intensas tais atividades no exterior ocorrem até os dias atuais.

Outro esforço em âmbito continental ocorreu a partir de recomendações do Grupo de Trabalho "Datum Vertical” (GT-III) do então Projeto SIRGAS (Sistema de Referência Geocêntrico para a América do Sul) que propôs a adoção de um arcabouço altimétrico homogêneo para o continente, denominado Sistema Vertical SIRGAS (SVSIRGAS), o qual seria definido por meio de dois conjuntos de altitudes: geométricas e físicas; estas obtidas a partir da inserção da componente gravimétrica (SIRGAS, 2005; Luz, 2008; IBGE, 2015). Com base nessas premissas o IBGE estabeleceu o Projeto Macro Circuitos, que agregava informações gravimétricas às altimétricas, em circuitos da RAAP estrategicamente selecionados, objetivando a materialização do SVSIRGAS em terras brasileiras e visando futuras conexões com os países lindeiros. Em paralelo, o IBGE estabeleceu como diretriz para seus levantamentos gravimétricos as novas linhas de nivelamento geométrico (Luz, 2008).

Atualmente, o IBGE é a instituição que mais produz gravimetria com objetivos geodésicos no Brasil e possivelmente no continente. Além disso, exerce papel de liderança junto a diversos países da América do Sul, capacitando profissionais e auxiliando no desenvolvimento das respectivas redes nacionais de gravidade. Adicionalmente, indo ao encontro da comunidade usuária, esforços estão sendo envidados para que, a partir do MAPGEO2015 (Matos et al., 2016), as atualizações do modelo geoidal brasileiro se tornem mais frequentes. Com quase sessenta anos de atividades gravimétricas, são mais de 42.000 estações medidas em território nacional, conforme mostra o cartograma inserido na figura 19.

\section{CONCLUSÕES}

Embora haja circunstâncias adversas, algumas delas mencionadas no corpo deste artigo, o cenário gravimétrico nacional é alvissareiro. A cada dia que passa novas utilidades para a gravimetria têm sido descobertas, ampliando o rol de aplicações em variados ramos de atividade, mormente os de cunho ambiental.

As missões gravimétricas satelitais ampliaram os horizontes com respeito à determinação da forma da Terra. Levantamentos aerogravimétricos vêm sendo empreendidos em áreas ermas e praticamente inacessíveis por terra. Informações gravimétricas provenientes do ambiente oceânico estão cada vez mais precisas e podem ser agregadas aos dados terrestres, aéreos e espaciais na busca incessante de um modelo geoidal mais conveniente ao território brasileiro. 


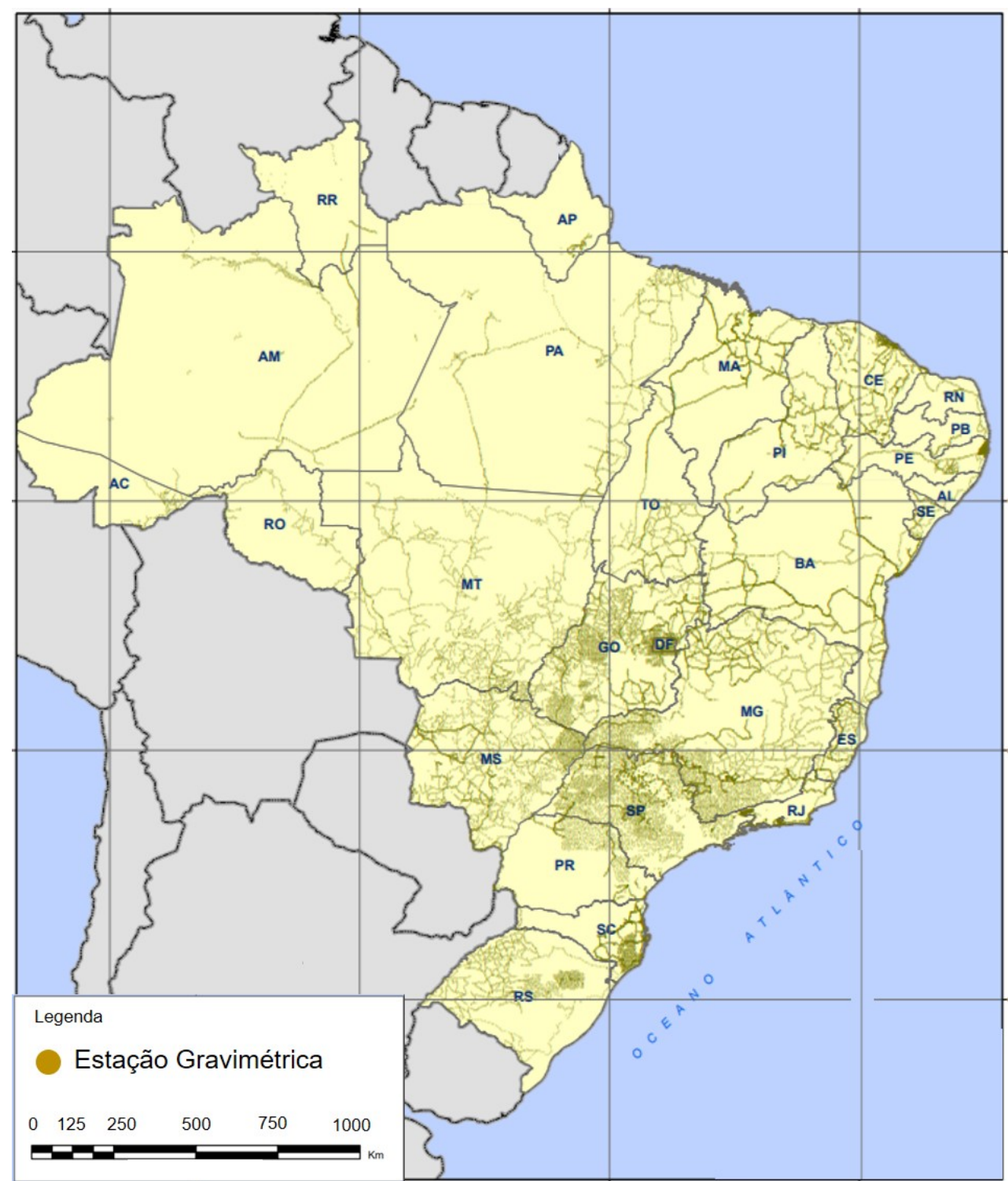

Figura 19 - Estações gravimétricas medidas pelo IBGE (https://www.ibge.gov.br)

Simultaneamente, começa a ganhar volume a ideia de se estabelecer uma Política Gravimétrica Nacional, cujo primeiro passo concreto, apesar de indireto, foi a criação do BNDG, iniciativa impar que congrega as principais instituições produtoras e usuárias. Tudo leva a crer que, no âmbito deste fórum interinstitucional e multidisciplinar, venham a ocorrer as desejáveis orientações que resultem em diretrizes gravimétricas concatenadas que o país se ressente em não ter.

Hoje o Brasil exerce um papel de destaque no continente Sul-Americano. Nos últimos quinze anos, equipes brasileiras têm atuado junto à maior parte dos países vizinhos, ajudando no estabelecimento dos respectivos sistemas gravimétricos nacionais e repassando orientações metodológicas de trabalho. Profissionais ilustres como Camil Gemael, recém-falecido, e Denizar Blitzkow, exemplos de devoção às lides gravimétricas, levaram ao país e ao mundo contribuições pioneiras e significativas, permitindo que jovens valores doravante assumam, em condições mais propicias, as rédeas técnico-científicas reivindicadas pela gravimetria.

O IBGE, enquanto gestor do SGB, assumiu uma postura mais proativa com relação às suas incumbências gravimétricas. Desde o início dos anos 1990, tem densificado sistematicamente vários recantos do país e do continente. No âmbito do comitê SIRGAS o IBGE desempenha tarefas relevantes voltadas à unificação geodésica continental.

Em cooperação científica com a EPUSP, prepara-se agora para disponibilizar periodicamente à sociedade versões atualizadas e validadas de modelos geoidais brasileiros. 
Além disso, colabora com algumas unidades da federação na estruturação dos sistemas geodésicos estaduais correspondentes.

Pensando no amanhã, o IBGE interage com vários segmentos da gravimetria brasileira e continental, visando conceber uma estratégia futura de ação. Com base nos dados existentes no BNDG, a Gerência da Rede Gravimétrica e
Desenvolvimento do Geoide (GRGG), apresentou uma análise interessante contida no cartograma inserido na figura 20, na qual há cerca de $60 \%$ do território com algum tipo de cobertura gravimétrica. Nota-se que, dos quase 40\% restantes, há vazios em Terras Indígenas (TI) e Unidades de Conservação (UC), a grande maioria no seio da Amazônia Legal.

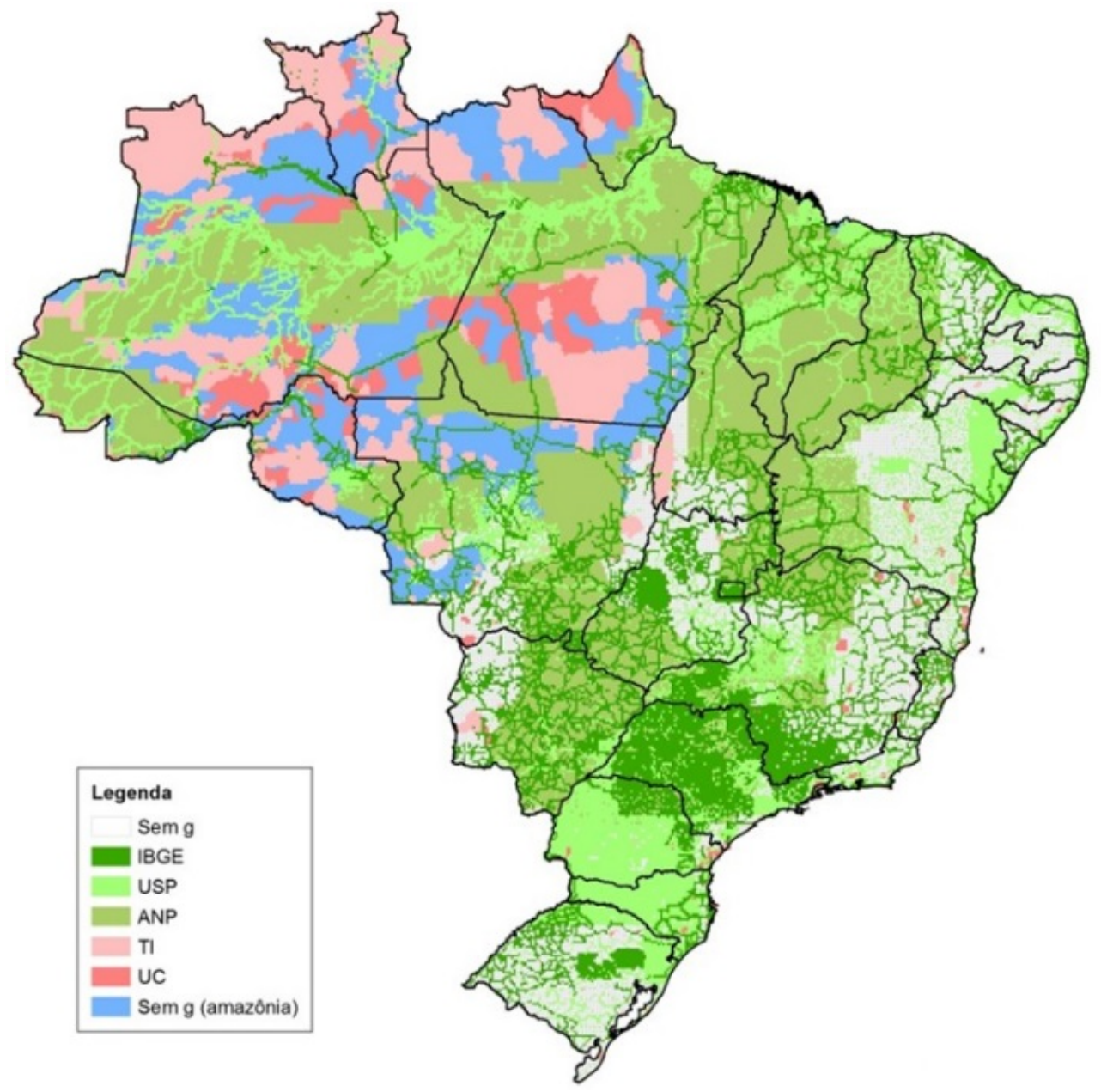

Figura 20 - Panorama gravimétrico multi-institucional brasileiro (Nunes, 2015).

Pensando no amanhã, o IBGE interage com vários segmentos da gravimetria brasileira e continental, visando conceber uma estratégia futura de ação. Com base nos dados existentes no BNDG, a Gerência da Rede Gravimétrica e Desenvolvimento do Geoide (GRGG), apresentou uma análise interessante contida no cartograma inserido na figura 20, na qual há cerca de $60 \%$ do território com algum tipo de cobertura gravimétrica. Nota-se que, dos quase 40\% restantes, há vazios em Terras Indígenas (TI) e Unidades de Conservação (UC), a grande maioria no seio da Amazônia Legal.

Segundo Nunes (2015), o IBGE idealizou linhas de ação que anteveem como melhorar a distribuição gravimétrica nacional e assegurar a consistência dos futuros modelos geoidais brasileiros. Assim sendo, pretende envidar esforços no sentido de contemplar esses vazios existentes, envolvendo diversas modalidades de aquisição gravimétrica. Da maneira como está concebido o panorama futuro, cabe à gravimetria atuar como instrumento de agregação, superando barreiras institucionais e diplomáticas, a fim de possibilitar uma desejável homogeneização geodésica continental, permitindo que o Brasil e os países sul-americanos possam ter uma referência única para subsidiar as atividades desenvolvidas nas respectivas zonas fronteiriças, com exatidão compatível com as necessidades requeridas pelos diversos segmentos da comunidade científica e usuária. 


\section{REFERÊNCIAS}

AGÊNCIA NACIONAL DE PETRÓLEO GÁS NATURAL E BIOCOMBUSTÍVEIS. ANP. BDEP. BNDG. Disp. em: http://www.anp.gov.br/.

BLITZKOW, D.; MATOS, A.C.O.C.; GUIMARÃES, G. N.; PACINO, M.C.; LAURIA, E.A.; NUNES, M.A.; CASTRO JUNIOR, C.A.C.; FLORES, F.; GUEVARA, N.H.; ALVAREZ, R.; HERNANDEZ, J.N. Gravity and Geoid Model for South America. In: EUROPEAN GEOSCIENCES UNION GENERAL ASSEMBLY 2016, Viena. EGU Proceedings...Viena: 2016

BRUINSMA, S. L., FORSTE, C., ABRIKOSOV, O., MARTY, J. C., RIO, M. H., MULET, S., BONVALOT, S. The new ESA satellite-only gravity field model via the direct approach. Geophysical Research Letters, v. 40, n. 14, p. 3607-3612, 2013.

CASTRO JÚNIOR, C.A.C. Contribuição ao estabelecimento de um sistema gravimétrico para a América do Sul. São Paulo, 2005. 156p. Dissertação (Mestrado em Engenharia de Transportes), Escola Politécnica, USP.

COYAGO, R.R.D. Ajuste de la red de control basico vertical en funcion de numeros geopotenciales. Sangolquí, Ecuador, 2010. 108p. Proyecto de grado previo a la obtención del título de ingenieria, Ingenieria Geografica y del Medio Ambiente. Escuela Politecnica del Ejército.

CPRM. SERVIÇO GEOLÓGICO DO BRASIL. Apresentação Sobre a CPRM. Disp. em: <http://www.cprm.gov.br/>.

DEHLINGER, P. Marine Gravity. Amsterdam, 1978. 322p. Elsevier Scientific Publishing Company.

EUROPEAN SPACE AGENCY. ESA. Gravity Mission GOCE. Disp. em: <http://www.esa.int/ Our_Activities/ Observing_the_Earth/GOCE $>$.

FAIRHEAD, D.; GREEN, C.; ODEGARD, M. Satellitederived gravity having an impact on marine exploration. The Leading Edge. Society of Exploration Geophysicists, v. 20, n 8, p. 873 - 876, 2001.

FÖRSTE, C.; BRUINSMA, S.L.; ABRIKOSOV, O.; LEMOINE, J.M.; MARTY, J.C.; FLECHTNER, F.; BALMINO, G.; BARTHELMES, F., BIANCALE, R. EIGEN-6C4 The latest combined global gravity field model including GOCE data up to degree and order 2190 of GFZ Potsdam and GRGS Toulouse. GFZ Data Services, 2014.

FÖRSTE, C. \& BRUINSMA, S.L. EIGEN-6S4 A timevariable satellite-only gravity field model to $d / 0300$ based on LAGEOS, GRACE and GOCE data from the collaboration of GFZ Potsdam and GRGS Toulouse. Disp. em: http://doi.org/10.5880/icgem.2016.004, 2016

FREITAS, S.R.C. Atividades gravimétricas da UFPR [mensagem pessoal]. Mensagem enviada por Silvio Rogério Correia de Freitas, Professor Doutor do Curso de PósGraduação em Ciências Geodésicas, UFPR, <sfreitas350@gmail.com>. Em 10 jun. 2015.

GALBIATTI, H.; BRAGA, M.A.; CARLOS, D.U.; SOUSA, R.R. Sistemas aerogravimétricos gradiométricos 3D-FTG e Falcon na exploração de minério de ferro. Revista Brasileira de Geofísica: Sociedade Brasileira de Geofísica, ano 4, n’ 29, p. 801-810, 2011.

GEMAEL, C. Introdução à Geodésia Física. Curitiba,1999. 302p. Editora da Universidade Federal do Paraná.

GEOFÍSICA BRASIL. Banco Nacional de Dados Gravimétricos Terrestres. Disp. em: http://geofisica brasil.com/eventos/90-congresso/2252-banco-nacional-dedados-gravimetricos-terrestres.html.

GEOFORSCHUngSZENTRUM. GFZ Potsdan. The CHAMP Satellite. Disp. em: http://op.gfzpotsdam.de/champ/systems/index_SYSTEMS.html.

GEOFORSCHUngszentruM. GFZ Potsdan, The GRACE Mission. Disp. em: http://op.gfz-potsdam.de/grace.

GOMES, R.A.A.D. \& MOTTA, A.C. Projeto Levantamento
Gravimétrico no Estado da Bahia. Relatório Final. Textos e Mapas. Salvador, CPRM. Convênio DNPM/CPRM, 140p. 1980. HILDENBRAND, J.D. Aerogeofísica no Brasil e a evolução das tecnologias nos últimos 50 anos. In: SIMPÓSIO DE GEOFÍSICA DA SOCIEDADE BRASILEIRA DE GEOFÍSICA, I, São Paulo, 2002. Anais... São Paulo: SBGeof.

INSTITUTO BRASILEIRO DE GEOGRAFIA E ESTATÍSTICA. Geociências. Sistema Geodésico Brasileiro. Rede Gravimétrica. Disp. em: http://www.ibge.gov.br/home/ geociencias/geodesia/gravimetrica.shtm.

INTERNATIONAL CENTRE FOR GLOBAL EARTH MODELS. Gravity Fields Models. Disp. em: http://icgem.gfz-potsdam.de/tom_longtime.

JET PROPULSION LABORATORY. JPL. Next-generation GRACE satellites arrive at launch site. Disp. em $<$ https://phys.org/news/2017-12-next-generation-gracesatellites-site.html.

LOBIANCO, M.C.B. Determinação das alturas do geoide no Brasil. São Paulo, 2005. 165p. Tese (Doutorado em Engenharia de Transportes), Escola Politécnica, USP.

LUZ, R.T. Estratégias para modernização da componente vertical do Sistema Geodésico Brasileiro e sua integração ao SIRGAS. Curitiba, 2008. 207p. Tese (Doutorado em Ciências Geodésicas), Universidade Federal do Paraná, Setor de Ciências da Terra.

MARINHA DO BRASIL. LEPLAC - Limite Exterior da Plataforma Continental Brasileira. Disp. em: https://www1.mar.mil.br/dhn/?q=leplac.

MATOS, A.C.OC.; BLITZKOW, D.; GUIMARÃES, G.N.; LOBIANCO, M.C.B.; COSTA, S.M.A. Validação do MAPGEO2010 e comparação com modelos do geopotencial recentes. Boletim de Ciências Geodésicas. Curitiba, v. 18, n. 1, p. 101-122, 2012.

MATOS, A.C.O.C. \& BLITZKOW, D. Modelagem Digital de Terrenos (MDT) de 3" para a América do Sul. PósDoutorado, Escola Politécnica da Universidade de São Paulo, São Paulo, 2008.

MATOS, A.C.O.C. Implementação de modelos digitais de terreno para aplicações na área de Geodésia e Geofísica na América do Sul. São Paulo, 2005. 355p. Tese (Doutorado em Engenharia), Escola Politécnica da Universidade de São Paulo, São Paulo.

MATOS, A.C.O.C.; BLITZKOW, D.; MACHADO, W.C.; NUNES, M.A.; LENGRUBER, N.V.; XAVIER, E.M.L.; FORTES, L.P.S. MAPGEO2015: o novo modelo de ondulação geoidal do Brasil. Revista Brasileira de Cartografia, v. 68, n. 10, 2016

MELLO, M.P. Sistema Geodésico Brasileiro: ensaio para definição do vetor de orientação geocêntrica através da geodésia física. Curitiba, 1973. 268p. Dissertação (Mestrado em Ciências Geodésicas), Universidade Federal do Paraná, Curso de Pós-graduação em Ciências Geodésicas.

MOREIRA, I.C. A expedição de Couplet à Paraíba: 1698. Revista da Sociedade Brasileira de História da Ciência, São Paulo, v. 5, p. 23-31, 1991.

MORELLI, C.; GANTAR, C.; McCONNELL R.K.; UOTILA, $\mathrm{U}$. The international gravity standardization network IGSN 71. Paris: Bureal Central de l'Association Internationale de Géodésie, 194p., 1971.

NUNES, M.A. Modelo Geoidal 2015. Palestra proferida por ocasião do Encontro de Gerências Regionais de Geodésia e Cartografia, Rio de Janeiro: IBGE, CDDI, 2015.

OBSERVATÓRIO NACIONAL. ON. (Brasil). Rede Gravimétrica Fundamental Brasileira, 1976-1986. Departamento de Geofísica. Rio de Janeiro: ON, 1986. Disp. em: $<$ http://www.on.br/>.

PAOLO, F. Altimetria por satélite e gravimetria marinha na 
representação integrada do campo de gravidade na região costeira do Brasil. São Paulo, 2009, 76p. Dissertação (Mestrado em Geofísica), Instituto de Astronomia, Geofísica e Ciências Atmosféricas, Universidade de São Paulo.

PERSSON, A. The Coriolis Effect: Four centuries of conflict between common sense and mathematics, Part I: A history to 1885. In: HISTORY OF METEOROLOGY, 2, 2005, Norrköping. Proceedings...Norrköping: Department for Research and Development, Swedish Metereological and Hydrological Institute.

PINTO, L.G.R. Atividades gravimétricas da CPRM [mensagem pessoal]. Mensagem enviada por Luiz Gustavo Rodrigues Pinto, Divisão de Geofísica - DIGEOF, CPRM - Serviço Geológico do Brasil<luiz.pinto@cprm.gov.br>. Em 22 jun. 2015.

REIGBER, CH., SCHWINTZER, P., NEUMAYER, K.H., BARTHELMES, F., KÖNIG, R., FÖRSTE, CH., BALMINO, G., BIANCALE, R., LEMOINE, J.-M., LOYER, S., BRUINSMA, S., PEROSANZ, F., FAYARD, T. The CHAMP-only Earth Gravity Field Model EIGEN-2. Advances in Space Research, v. 31, n. 8, 1883-1888, 2003.

RIBAMAR, J.L.B. Atividades gravimétricas da ANP. [mensagem pessoal]. Mensagem enviada por José Ribamar Lopes Bezerra, Coordenador do BDEP / BNDG, Agência Nacional de Petróleo, Gás Natural e Biocombustíveis, <jbezerra@anp.gov.br>. Em 18 ago.2015.

RIGOTI, A. Proposta do comitê de aerogeofísica ao fórum para o desenvolvimento de métodos para a exploração mineral na Amazônia. Brazilian Journal of Geophysics, ano 2, n. 18, p. 215-228, 2000.

ROSIER, F.A. Medidas diferenciais da gravidade: ajustamento de uma subrede de estações gravimétricas e determinação de coeficientes de escala para os gravímetros La Coste \& Romberg modelo G no 41, 372 e 454. Curitiba, 1979. 190p. Dissertação (Mestrado em Ciências Geodésicas), Curso de Pós-graduação em Ciências Geodésicas, Universidade Federal do Paraná

SANDWELL, D.T.; MULLER, R.D.; SMITH, W.H.F.; GARCIA, E.; FRANCIS, R. New global marine gravity model from CryoSat-2 and Jason-1 reveals buried tectonic structure. Science: American Association for the
Advancement of Science, ano 65, n. 346, p. 65-67, 2014.

SANTOS JUNIOR, G. Rede gravimétrica: novas perspectivas de ajustamento, análise de qualidade e integração de dados gravimétricos. Curitiba, 2005. 172p. Tese (Doutorado em Ciências Geodésicas), Universidade Federal do Paraná, Curso de Pós-graduação em Ciências Geodésicas.

SCHWINTZER, P. \& REIGBER, C. The contribuition of GPS flight recievers to global gravity field recovery. Journal of Global Positioning Systems, v. 1, n. 1, 2002.

SISTEMA DE REFERENCIA GEOCÉNTRICO PARA LAS AMÉRICAS. SIRGAS. Boletín Informativo n. 8, 2005.

SISTEMA DE REFERENCIA GEOCÉNTRICO PARA LAS AMÉRICAS. SIRGAS. Presentación. 2015. Disp. em: < http://www.sirgas.org/index.php?id=64>.

SOUSA, M.A. Atividades gravimétricas do ON. [mensagem pessoal]. Mensagem enviada por Mauro Andrade de Sousa, Coordenação de Geofísica, Observatório Nacional. <mauro@on.br>. Em 30 maio 2015.

THOMAS, P.D. Background on Geodetic Principles and Theories. In: FIRST MARINE GEODESY SYMPOSIUM, 1966, Columbus. Proceedings... Columbus: Battelle Memorial Institute. 1966. p. 9-26.

TORGE, W. Gravimetry. New York, USA: Ed. Walter de Gruyter. 1989. 453 p.

TORGE, W. Geodesy. 3. compl. rev. and ext. ed. Berlin: Walter de Gruyter, 2001. xv, 416p.

TORGE, W.; TIMMEN, L.; RÖDER, R.H.; SCHNÜLL, M. Large Scale Absolute Gravity Control in South America JILAG-3 Campaigns 1988-1991. Report The IFE Absolut Gravity Program “South America” 1988-1991, 45p. München, 1994.

TRABANCO, J.L.A. Ajustamento e homogeneização de redes gravimétricas fundamentais regionais. São Paulo, 1995. 109 p. Dissertação (Mestrado em Engenharia), Escola Politécnica, Universidade de São Paulo.

Submetido em 25 de outubro de 2017 Aceito em 24 de janeiro de 2018 